\title{
Increased West Antarctic and unchanged East Antarctic ice discharge over the last 7 years
}

\author{
Alex S. Gardner ${ }^{1}$, Geir Moholdt ${ }^{2}$, Ted Scambos ${ }^{3}$, Mark Fahnstock $^{4}$, Stefan Ligtenberg ${ }^{5}$, Michiel van den Broeke ${ }^{5}$, \\ and Johan Nilsson ${ }^{1}$ \\ ${ }^{1}$ Jet Propulsion Laboratory, California Institute of Technology, Pasadena, CA 91109, USA \\ ${ }^{2}$ Norwegian Polar Institute, Fram Centre, 9296 Troms $\varnothing$, Norway \\ ${ }^{3}$ National Snow and Ice Data Center (NSIDC), University of Colorado at Boulder, Boulder, CO 80303, USA \\ ${ }^{4}$ Geophysical Institute, University of Alaska Fairbanks, Fairbanks, AK 99775, USA \\ ${ }^{5}$ Institute for Marine and Atmospheric research Utrecht (IMAU), Utrecht University, Utrecht, the Netherlands
}

Correspondence: Alex S. Gardner (alex.s.gardner@jpl.nasa.gov)

Received: 25 April 2017 - Discussion started: 4 May 2017

Revised: 21 November 2017 - Accepted: 27 November 2017 - Published: 13 February 2018

\begin{abstract}
Ice discharge from large ice sheets plays a direct role in determining rates of sea-level rise. We map presentday Antarctic-wide surface velocities using Landsat 7 and 8 imagery spanning 2013-2015 and compare to earlier estimates derived from synthetic aperture radar, revealing heterogeneous changes in ice flow since $\sim 2008$. The new mapping provides complete coastal and inland coverage of ice velocity north of $82.4^{\circ} \mathrm{S}$ with a mean error of $<10 \mathrm{~m} \mathrm{yr}^{-1}$, resulting from multiple overlapping image pairs acquired during the daylight period. Using an optimized flux gate, ice discharge from Antarctica is $1929 \pm 40$ Gigatons per year $\left(\mathrm{Gt} \mathrm{yr}^{-1}\right)$ in 2015, an increase of $36 \pm 15 \mathrm{Gt} \mathrm{yr}^{-1}$ from the time of the radar mapping. Flow accelerations across the grounding lines of West Antarctica's Amundsen Sea Embayment, Getz Ice Shelf and Marguerite Bay on the western Antarctic Peninsula, account for $88 \%$ of this increase. In contrast, glaciers draining the East Antarctic Ice Sheet have been remarkably constant over the period of observation. Including modeled rates of snow accumulation and basal melt, the Antarctic ice sheet lost ice at an average rate of $183 \pm 94 \mathrm{Gt} \mathrm{yr}^{-1}$ between 2008 and 2015 . The modest increase in ice discharge over the past 7 years is contrasted by high rates of ice sheet mass loss and distinct spatial patters of elevation lowering. The West Antarctic Ice Sheet is experiencing high rates of mass loss and displays distinct patterns of elevation lowering that point to a dynamic imbalance. We find modest increase in ice discharge over the past 7 years, which suggests that the recent pattern of mass loss in Antarc-
\end{abstract}

tica is part of a longer-term phase of enhanced glacier flow initiated in the decades leading up to the first continent-wide radar mapping of ice flow.

\section{Introduction}

The Antarctic ice sheet receives roughly $2000 \mathrm{Gt}(\sim 5.5 \mathrm{~mm}$ sea-level equivalent) of precipitation each year with $>90 \%$ of this mass leaving as solid ice discharge to the ocean and the remaining $<10 \%$ leaving in the form of sublimation, wind-driven snow transport, meltwater runoff and basal melt. Recent studies indicate significant mass loss from the Antarctic ice sheet that is likely accelerating (Harig and Simons, 2015; Helm et al., 2014; Martín-Español et al., 2016; McMillan et al., 2014; Rignot et al., 2011b; Shepherd et al., 2012; Velicogna, 2009). Understanding how this imbalance evolves is critical to providing meaningful projections of sea-level change. A major hurdle for improved attribution of mass changes determined from gravimetry and/or altimetry, and in determining mass changes themselves from the mass balance approach, is the difficulty in resolving continent-wide changes in ice discharge at high precision and accuracy for multiple epochs. This requires circum-Antarctic measurements of surface velocity on fine spatial scale and with sufficient accuracy $\left(\sim 10 \mathrm{~m} \mathrm{yr}^{-1}\right)$ to observe regionally coherent changes in flow. 
Earlier circum-Antarctic mappings of surface velocity have been based on synthetic aperture radar (SAR) data with incomplete coverage for 1996-2000 (Jezek et al., 2003; Rignot, 2006) and near-complete coverage for 2007-2009 (Rignot et al., 2011a). Applications of optical imagery for surface velocity mapping have heretofore been limited to more local scales (e.g., Bindschadler and Scambos, 1991; Scambos et al., 1992) due to limited sensor capabilities, cloudiness and too few repeat-image acquisitions. Improvements in sensor technology (particularly in radiometric resolution) and far higher image acquisition rates for Landsat 8 , launched in 2013, largely overcome these limitations (Fahnestock et al., 2015; Jeong and Howat, 2015; Mouginot et al., 2017) and provide the ability to generate near-complete yearly mappings of surface velocity with high accuracy $\left(\sim 10 \mathrm{~m} \mathrm{yr}^{-1}\right)$.

Here we describe the application of two newly developed and independent feature tracking methodologies (JPL and NSIDC) that we applied to hundreds of thousands of Landsat image pairs covering the entire Antarctic ice sheet north of $82.4^{\circ} \mathrm{S}$, producing six near-complete mappings of ice sheet surface velocities in both the 2013-2014 and 2014-2015 austral polar daylight periods. By differencing these velocity fields with the earlier SAR mapping (Rignot et al., 2011a) we resolve changes in ice surface velocity for the 7-year period between circa 2008 and 2015. Velocity changes are then used to estimate ice discharge on the basin scale and its change through time. For the determination of ice discharge we provide a novel approach to defining the cross-sectional area of ice flow (flux gate; Sect. 2.2) that greatly reduces uncertainties in estimates of ice discharge. By differencing estimates of ice discharge and basal melt rates (Van Liefferinge and Pattyn, 2013) from published estimates of the surface mass balance (van Wessem et al., 2016, 2014) we are able to estimate the net mass balance of the ice sheet on the basin scale, revealing recent patters of ice sheet imbalance.

\section{Methods}

\subsection{Surface velocity}

Glacier velocities were determined by feature tracking of matching path-row Landsat Collection $0 \mathrm{~L} 1 \mathrm{~T}$ and L1GT image pairs in the panchromatic Band 8 (15 m pixel size) using normalized cross correlation (NCC). To assess the sensitivity of our results to choices in Landsat processing methodology (e.g., search template size, spatial resolution, geolocation offset correction, data filtering, image-pair date separation and compositing) we examine multiple velocity mosaics derived from two independent processing methodologies developed by JPL and NSIDC (Fig. 1). Uncertainties in velocities were determined by comparing Landsat and SAR velocities measured at flux-gate nodes for basins with minimal change in ice discharge (basins B1-19 and B27), i.e., where velocity differences are assumed to be indicative measure- ment uncertainty. Uncertainties in velocities can be as high as $20-30 \mathrm{~m} \mathrm{yr}^{-1}$ locally but are largely uncorrelated on basin scales (>1000 km; see Appendix A for validation of the velocity fields). All velocity mosaics are freely downloadable from the NSIDC (National Snow and Ice Data Center). JPL and NSIDC processing chains share many of the same characteristics, with main differences being how the image-pair data are corrected for geolocation errors, how the imagery is searched for matching features and the choice of search parameters such as template size and spacing.

\subsubsection{JPL auto-RIFT}

\section{Image-pair pixel offsets}

The autonomous Repeat Image Feature Tracking (autoRIFT v0.1) processing scheme was applied to all Landsat 7 and 8 images acquired between August 2013 and May 2016 with $80 \%$ cloud cover or less. Images were preprocessed using a 5 by 5 Wallis operator to normalize for local variability in image radiance caused by shadows, topography and sun angle. All image pairs with less than 910-day separation were searched. Preprocessed image pairs were searched for matching features by finding local NCC maxima at subpixel resolution using Taylor refinement (Paragios et al., 2006) within a specified search distance. A sparse (1/16 of full search) NCC search was first used to determine areas of coherent correlation between image pairs. Results from the sparse search guide a dense search with search centers spaced such that there is no overlap between adjacent template search chips (i.e., the distance between template centers is equal to the template size). Highest-quality image pairs $(<20 \%$ cloud and $<1$-year separation) were searched using this approach, with a large search distance centered at zero pixel offset with a 32 by 32 pixel template chip. Spatially resolved statistics (mean and standard deviation of $x$ and $y$ displacements) are then used to guide a dense image search of all imagery with $16 \times 16$ or $32 \times 32$ pixel template chips depending on expected gradients in surface velocities. Areas of unsuccessful retrievals were searched with progressively increasing template chip sizes of 32, 64 and 128 that increase the signal to noise at the expense of spatial resolution.

Successful matches were identified using a novel normalized displacement coherence (NDC) filter. In this approach filtering is applied on search-normalized displacements, i.e., displacements divided by the NCC search distance. Normalized displacements are accepted if 7 or more of the values within a 5 by 5 pixel centered window are within one-quarter of a search distance for both $x$ and $y$ displacement components. This acceptance criterion is iterated on three times. Finally an iterative (two times) filter is applied to remove the few number of displacements that are retained by random agreement with neighbors. For this filter, displacements are compared to the centered 5 by 5 window median. Only values that agree within 4 times the centered 5 by 5 window 


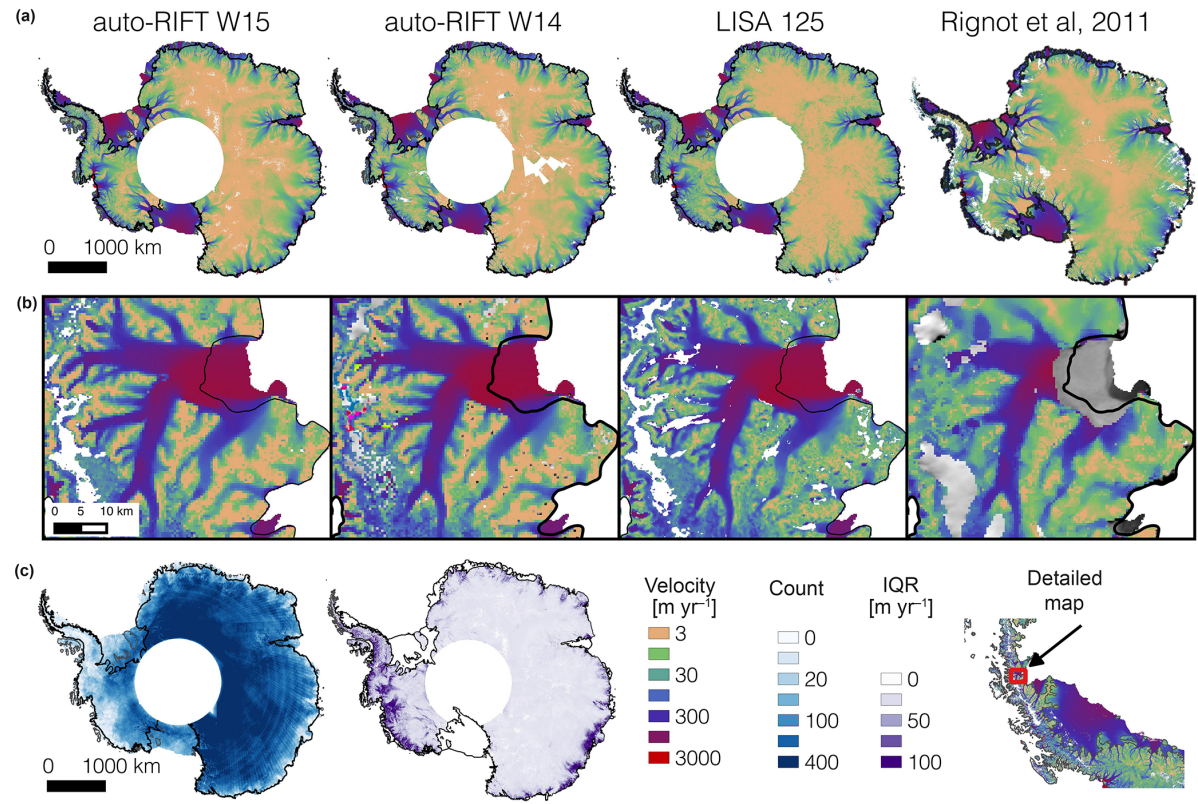

Figure 1. Comparison between JPL auto-RIFT error-weighted average, NSIDC LISA $125 \mathrm{~m}$ and Rignot et al. (2011a) surface velocities. Panel a shows Antarctic-wide velocities; panel b shows close-ups of the Hektoria Glacier, located on the eastern side of the Antarctic Peninsula for spatial detail; and panel $\mathbf{c}$ shows valid image-pair velocity counts and their interquartile range (IQR) for the auto-RIFT W15 mosaic. Formal errors produced by auto-RIFT are unrealistically low so we display the IQR as a proxy for the per-pixel random error.

mean absolute deviation are retained. The NDC filtering approach is highly generic and very effective at removing random image-pair matches but not at removing match blunders that can result in spatially coherent errors. Remaining blunders are filtered during the merging process using information from all image pairs.

Image-pair pixel displacements were calculated from georeferenced images that are in Antarctic Polar Stereographic (EPSG 3031) projection. This introduces scale distortions that increase with distance from the latitude of origin $\left(71^{\circ} \mathrm{S}\right)$. We corrected for this scale distortion when converting from pixel displacement to velocity following the equations presented in Snyder (1987).

Image geometry between image pairs is highly stable, but images suffer from large $x$ and $y$ geolocation errors $(\sim 15 \mathrm{~m})$. This resulted in good gradients in velocity but poor absolute velocity. Displacement fields were also contaminated by match blunders (e.g., matching along shadow edges or of surfaces obscured by cloud in one of the two images). Therefore, displacement fields required heavy post-processing to isolate the geophysical signal. This was done by stacking all timenormalized displacements (velocities), co-registering them over stationary or slow flowing surfaces and filtering based on the interquartile range (IQR) determined for each pixel of the displacement stack. All $x$ and $y$ displacements that fell outside of the range $Q_{1}-T \times \mathrm{IQR}$ to $Q_{3}+T \times \mathrm{IQR}$ were culled from the data set, where $Q_{1}$ and $Q_{3}$ are the first and third quartile, respectively, and $T$ is a scalar that defines the acceptance threshold.

\section{Reference velocity}

A reference velocity $\left(V x_{0}, V y_{0}\right)$ field was generated from all individual image-pair velocities. As a first step, gross outliers were removed from the unregistered data by setting $T$ equal to 3. Stacked displacement fields were then coregistered by iteratively correcting for the median $x$ and $y$ velocity difference between individual image-pair velocities and static reference velocity fields ( $V x_{\text {ref }}$ and $\left.V y_{\text {ref }}\right)$ over stationary or slow flowing surfaces, stopping after five iterations. For each iteration, coregistered displacements were filtered setting $T$ equal to 1.5 , and the effective template chip size (resolution of the velocity field) was coarsened for low-velocity gradients $\left(<10 \mathrm{~m} \mathrm{yr}^{-1}\right.$ between adjacent search chips) to minimize high-frequency noise while retaining spatial gradients.

Initial $V x_{\text {ref }}$ and $V y_{\text {ref }}$ were defined as all grounded ice pixels with median velocities $<10 \mathrm{~m} \mathrm{yr}^{-1}$ and with $>100$ valid retrievals. Where these conditions were not met, $V x_{\text {ref }}$ and $V y_{\text {ref }}$ were supplemented with Rignot et al. (2011a) velocities $<10 \mathrm{~m} \mathrm{yr}^{-1}$. Additionally, all pixels containing exposed rock were initially assigned a $V x_{\text {ref }}$ and $V y_{\text {ref }}$ of $0 \mathrm{~m} \mathrm{yr}^{-1}$. Exposed rock was identified using the SCAR Antarctic Digital Database (Thomson and Cooper, 1993; Fig. 2). The initial template chip size was set to the minimum chip size for which $40 \%$ of the valid displacements in the stack were determined using a chip of that size or smaller. After each coregistration of the data, $V x_{\text {ref }}$ and $V y_{\text {ref }}$ were set equal to the error-weighted velocity for those pixels that have velocities $<50 \mathrm{~m} \mathrm{yr}^{-1}$ and a $V x$ and $V y$ 




Figure 2. Antarctic ice sheet velocities overlain on the MODIS Mosaic of Antarctica (Scambos et al., 2007). Areas of imposed zero change in velocity are shown in cyan. Areas of prescribed zero surface velocity (rock outcrops) are shown in red as defined according to the Antarctic Digital Database (http://www.add.scar.org).

$\mathrm{IQR}<40 \mathrm{~m} \mathrm{yr}^{-1}$. All pixels containing exposed rock are reassigned a $V x_{\text {ref }}$ and $V y_{\text {ref }}$ of $0 \mathrm{~m} \mathrm{yr}^{-1}$. The uncertainty of each image-pair velocity field was determined as the standard deviation of the residuals to $V x_{\text {ref }}$ and $V y_{\text {ref. }}$. When there were fewer than 320 coregistration pixels within an image pair, the uncertainty was set to the RSS (root of sum of squares) of the pointing uncertainty of each image.

\section{JPL auto-RIFT annual fields}

All image-pair velocities for a given year $Y$ (center date of image pair $>15$ July, $Y-1$ and $<15$ July $Y$ ) were coregistered using the reference velocity field $\left(V x_{0}, V y_{0}\right)$, where $V x_{\text {ref }}$ and $V y_{\text {ref }}$ were set equal to the error-weighted velocity $\left(V x_{0}, V y_{0}\right)$ for those pixels that have velocities $<50 \mathrm{~m} \mathrm{yr}^{-1}$ and $V x_{0}$ and $V y_{0} \mathrm{IQR}<40 \mathrm{~m} \mathrm{yr}^{-1}$. Annual error-weighted averages and median velocities were first calculated setting the filter limits based on the quartile ranges of $V x_{0}$ and $V y_{0}$ and setting $T=3$. Velocities were further refined by setting the filter limits based on the quartile ranges of initial annual values and using a more stringent acceptance threshold of $T=1.5$.

Using this approach we calculated four nearly complete Landsat 8 velocity maps: median (M) and error-weighted average (W) velocities for years 2014 and 2015. The 2014 and 2015 velocities were derived from $\sim 100000$ and $\sim 200000$ unique image pairs, respectively (Fig. 1).

\subsubsection{NSIDC LISA}

NSIDC's Landsat ice speed for Antarctica processing (LISA v1.0) used the Python image correlation, PyCorr v1.10, described in detail by Fahnestock et al. (2015). PyCorr was applied to Landsat 8 data separated by 16 to 400 days, spanning 26 September 2013 to 1 April 2015 using a reference template size of $300 \times 300 \mathrm{~m}$ with $300 \mathrm{~m}$ spacing between search templates. Images were manually selected based on the proportion of cloud-free surface coverage from the group of images with less than $70 \%$ cloud cover. A highpass filter of approximately $250 \mathrm{~m}$ spatial scale was applied to the images to enhance surface detail and suppress topographic shading.

PyCorr outputs a quality metric delcorr, which is the difference between the regression coefficient of the peak match and the second-highest match outside of a $3 \times 3$ cell area around the peak. All displacement values with a delcorr value less than 0.15 were eliminated. Velocities are further filtered by examining the difference between the velocities at the assessed pixel with the eight surrounding values. Velocities with no neighbors were masked. Velocities with one neighbor were masked when the absolute difference between the two values was greater than $365 \mathrm{~m} \mathrm{yr}^{-1}$. Velocities with two neighbors were masked if they exceeded 3 standard deviations of the mean. Finally the standard deviation of each $3 \times 3$ region was computed, and the center pixel of each region was masked when the corresponding standard deviation is greater than $365 \mathrm{~m} \mathrm{yr}^{-1}$.

Image-pair geolocation errors were corrected using three sets of $x-y$ velocity offsets. Each set of offsets were computed over rock (http://www.add.scar.org) and near-zero ice $\left(<20 \mathrm{~m} \mathrm{yr}^{-1}\right)$ and low ice velocity $\left(<40\right.$ and $\left.>20 \mathrm{~m} \mathrm{yr}^{-1}\right)$ areas according to Rignot et al. (2011a). Offset corrections were then weighted by count and applied to individual image-pair results.

Resulting velocities for each image pair were bilinearly resampled to the target grid spacing of either 750 or $125 \mathrm{~m}$. These grids were then composited using a weighting scheme that favors the more accurate long-interval velocity determinations (16-day pairs, 0.3 weighting; 32-day pairs, 0.6 ; 48day pairs, $0.9 ;>48$-day pairs, 1.0$)$. Additionally, a weighting factor was applied to each cell based on the mean NCC and delcorr values. Mosaics were then corrected for projection scale distortion, stacked and combined in a weighted average scheme. The number of image pairs in the LISA v1.0 grid ranges from $\sim 10$ to over 200 (Fig. 1).

\subsection{Flux gates}

Estimation of ice flux from measurements of surface velocity requires knowledge of the vertical density profile, flow cross-sectional area (flux gate) and an assumption of the relationship between surface and depth-averaged velocity. The most accurate estimates of ice thickness come from radioecho-sounding (RES) measurements, but RES data only exist for about $19 \%$ of the ice sheet grounding line. For the calculation of discharge, we choose to compromise proximity to the grounding line for inclusion of more upstream RES data and for avoiding glacier shear zones with poorly constrained 


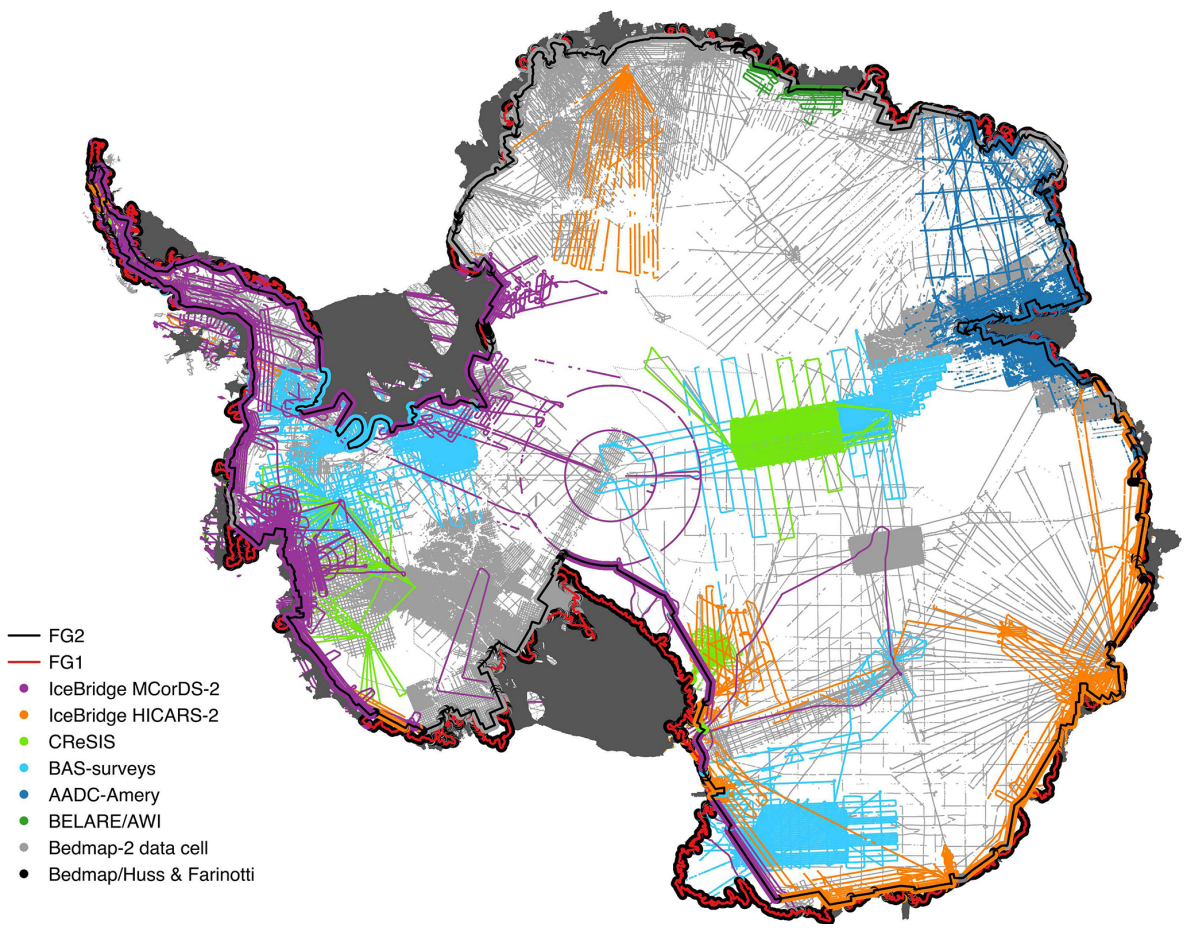

Figure 3. Radio-echo-sounding data used to compile flux gates FG1 and FG2. An overview of data used and their references is provided in Table 1 .

Table 1. Data sources and percentages for radio-echo-sounding data used to compile flux gates.

\begin{tabular}{lrrrl}
\hline Data set & GL0 & FGI & FG2 & Reference \\
\hline IceBridge MCoRDS-2 & $5.3 \%$ & $16.1 \%$ & $31.5 \%$ & Leuschen et al. (2010) \\
IceBridge HiCARS-2 & $2.1 \%$ & $5.4 \%$ & $20.2 \%$ & Blankenship et al. (2012) \\
CReSIS & $0.4 \%$ & $0.3 \%$ & $0.3 \%$ & Gogineni (2012) \\
BAS surveys & $1.7 \%$ & $7.4 \%$ & $9.0 \%$ & https://legacy.bas.ac.uk/data/aerogeo/ \\
AADC Amery & $2.6 \%$ & $2.5 \%$ & $12.1 \%$ & Allison and Hylland (2010) \\
BELARE/AWI & $0.1 \%$ & $2.4 \%$ & $4.1 \%$ & Callens et al. (2014, 2015) \\
Bedmap-2 data cell & $6.9 \%$ & $8.3 \%$ & $18.3 \%$ & Fretwell et al. (2013) \\
\hline Sum & $19.2 \%$ & $42.4 \%$ & $95.6 \%$ & \\
\hline
\end{tabular}

velocities. We do so by modifying the best-known grounding line to go inland of major shear zones and to follow nearby RES flight lines from which valid ice thickness data can be extracted. We prioritize the nearest and most recent RES data available from seven freely available data sets (Fig. 3 and Table 1). For flux gates with no RES data within $1 \mathrm{~km}$ distance, ice thickness values are extracted by bilinear interpolation from the ice thickness grid of Huss and Farinotti (2014) over the Antarctic Peninsula and Bedmap-2 (Fretwell et al., 2013) for the rest of Antarctica. We generate three alternative flux gates: a grounding-line flux gate (GL0) based on a synthesis of mappings of the grounding line, a lightly modified version of GL0 improved by following RES profiles upstream and in close proximity to the grounding line (FG1) and a flux-gate outline based solely on RES profiles in favorable positions for calculating flux (FG2).

GL0 is a best-assessment grounding-line position from a synthesis of incomplete data first presented in Depoorter et al. (2013) that has been updated here by more recent grounding-line mappings in the Amundsen Sea region (Rignot et al., 2014, 2011b) and for the Totten Glacier in East Antarctica (Li et al., 2015; Rignot et al., 2013); two highly dynamic regions with considerable ice fluxes and changes in grounding-line position. Ice thickness was mainly extracted from the gridded products of Bedmap-2 (67\%) and the Antarctic Peninsula (9\%), but also a considerable amount of RES data that were within $1 \mathrm{~km}$ (applied threshold) of the grounding line (19\%). For that, we also considered grid cells in Bedmap-2 that have been derived directly from RES data 
$(7 \%)$, as indicated in a data coverage mask. These thickness values have a much lower uncertainty (mean $68 \mathrm{~m}$ ) than the interpolated thicknesses in areas not covered by RES (mean $168 \mathrm{~m})$.

FG1 is a modified version of GL0 that follows RES flight lines (Fig. 3) or Bedmap-2 data cells that are in the vicinity of the grounding line. Whether or not to divert from the grounding line in favor of RES profiles was determined ad hoc rather than applying a strict distance threshold. Long, continuous RES profiles further apart were more likely to be followed than short, scattered RES data closer to the grounding line. In general, the modified parts of FG1 are within a few tens of kilometers from the GL0 and even less so in the Amundsen and Bellingshausen Sea coasts and the Filchner-Ronne ice shelf regions, where RES flight lines are often aligned with the grounding line. Almost all of these important regions are covered by RES data in FG1, and for Antarctica as a whole the RES coverage is $42 \%$ (Table 1). We found that FG1 was the most suitable flux-gate line for estimating changes in ice discharge due to its close proximity to the grounding line and high coverage of RES data.

FG2 is a modified version of FG1 that further prioritizes RES flight lines over proximity to the grounding line around the entire continent. Only slight modifications were made in regions like the Amundsen and Bellingshausen Sea coasts, the Filchner-Ronne ice shelf and Dronning Maud Land for which many near-grounding-line RES data exist, but for parts of East Antarctica and along the Transantarctic Mountains the modification can be several hundred kilometers (Fig. 3). The total coverage of RES data along FG2 is $96 \%$ (Table 1). We used this flux-gate line to estimate absolute discharge for the ice sheet, but not for assessing temporal changes in discharge, because they are often most pronounced near the grounding line that is better sampled by FG1.

The average point spacing along the three flux-gate lines is $198-265 \mathrm{~m}$, with a maximum spacing of $400 \mathrm{~m}$ to ensure sufficiently dense sampling of ice thickness and surface velocity for ice flux calculations (see Sect. 2.3 for a detailed discussion of resolution-dependent errors in flux calculations). Flux-gate points without RES data and within the rock mask of the SCAR Antarctic Digital Database $(<4 \%$; Thomson and Cooper, 1993; Fig. 2) were assigned a zero ice thickness. Since the thickness data were provided as physical ice thicknesses, we subtracted modeled average (1979-2015) firn air content (FAC; see Sect. 2.5) to obtain ice-equivalent thicknesses, assuming ice has a density of $917 \mathrm{~kg} \mathrm{~m}^{-3}$, relevant for ice flux calculations.

For further analyses, we also extracted point attributes for source data and year, surface elevation, FAC and all available thickness data. Histograms of ice thickness, uncertainties in ice thickness, date of thickness measurement, FAC, uncertainty in FAC, surface velocity, ice thickness change rate and uncertainty ice thickness change rate for all three flux gates are shown in Fig. 4. Flux gates and extracted ancillary data are available from the National Snow and Ice Data Center.

\subsection{Ice discharge}

We calculate ice flux $(F)$ by multiplying the $x$ and $y$ velocity component $(V x / y)$ by the width of the flux gate projected in the $x$ and $y$ coordinates $(W x / y)$ and ice-equivalent thickness $(H)$ at each flux node $(i)$ and summing

$F=\sum_{i=1}^{\mathrm{nn}}\left(V x_{i} W x_{i}+V y_{i} W y_{i}\right) H_{i}$,

where $\mathrm{nn}$ is the number of nodes at which ice flux is calculated. Here we defined the flux gate following polygon convention with the upstream side of the flux gate being defined as to the right-hand side of the polygon gate vector as one moves from node $n$ to node $n+1$. In this convention $W x$ is negative when $y_{n+1}>y_{n}$ and $W y$ is negative when $x_{n+1}<x_{n}$. Ice discharge $(D)$ at the grounding line of the ice sheet corresponds to $F$ for the GL0 flux gate. Applying mass conserving principles (Morlighem et al., 2011), $D$ is equal to $F+\mathrm{SMB}+\mathrm{d} V_{\mathrm{dyn}} / \mathrm{d} t$ for the FG1 and FG2 flux gates. SMB is the unmeasured flux due to a positive surface mass budget of the area between the flux gate and the grounding line and is estimated from RACMO2.3 climatology (1979-2015; see Sect. 2.4). SMB is corrected (reduced) for basal melt occurring between the flux gate and the grounding line which does not contribute to solid ice discharge (Van Liefferinge and Pattyn, 2013). $\mathrm{d} V_{\mathrm{dyn}} / \mathrm{d} t$ is the unmeasured flux due to ice flow convergence and divergence between the flux gate and the grounding line, which we refer to as the dynamic volume change. This is accounted for by assuming that firn corrected CryoSat-2 elevation change rates (Sect. 2.6) measured over ice moving at $>200 \mathrm{~m} \mathrm{yr}^{-1}$ that lies between the flux-gate and the grounding line can be attributed to dynamic volume change. Rates of volume change in 2008 and 2015 were extrapolated using the measured acceleration in the rate of elevation change over the period of CryoSat-2 data (20112015). Measured dynamic volume loss is considered to increase total discharge and vice versa. Uncertainty in the dynamic volume change can not be rigorously quantified and are therefore conservatively assumed to be $0.1 \mathrm{~m} \mathrm{yr}^{-1}$ times the area between the grounding line and the flux gate having a surface velocity $>200 \mathrm{~m} \mathrm{yr}^{-1}$ or $30 \%$ of the magnitude of the estimated dynamic volume change, whichever is larger. A velocity cutoff of $200 \mathrm{~m} \mathrm{yr}^{-1}$ was selected to separate volume changes resulting from changes surface mass balance and those resulting from changes in dynamics. This threshold is arbitrary. Even so, the dynamic volume change correction is very small and insensitive to the selected cutoff velocity.

Calculation of discharge is highly sensitive to the definition of the flux gate and to any vertical gradient in the ice flow (Chuter et al., 2017; Mouginot et al., 2014; Rignot, 2006; Rignot and Thomas, 2002). When calculating ice flux, we assume that there are no vertical gradients in ice velocity. This assumption introduces a small positive bias $(<0.4 \%)$ but is negligible relative to other sources of error. 

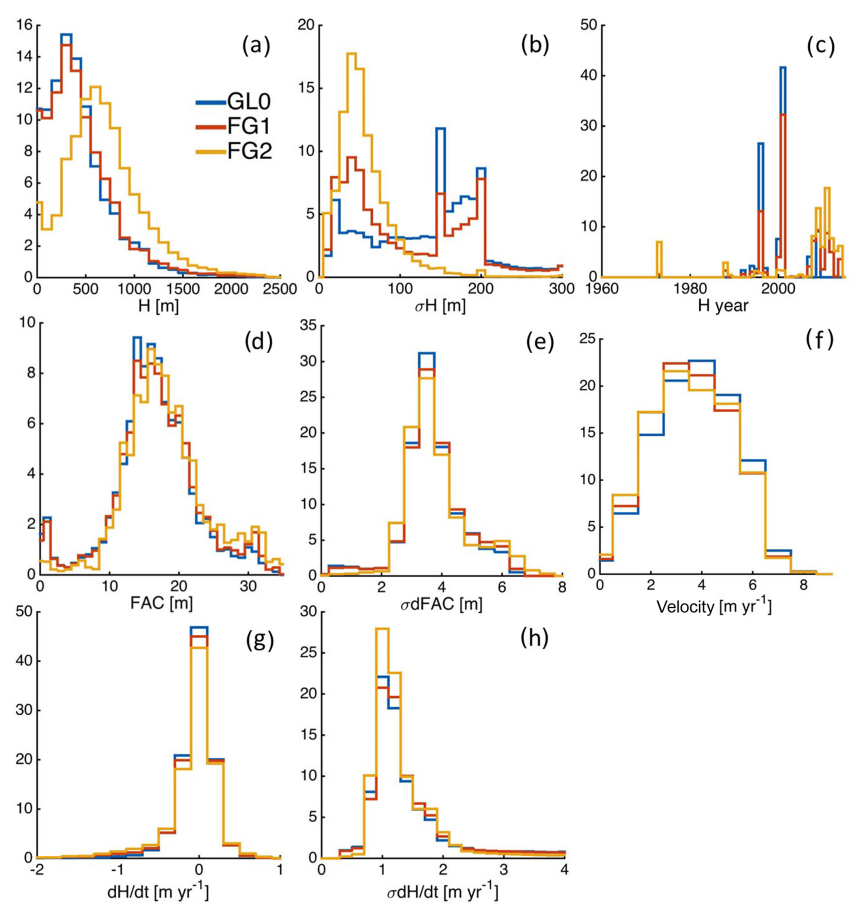

Figure 4. Histograms of ice-equivalent thickness (a), uncertainty in ice-equivalent thickness (b), year of ice thickness measurement (c), firn air content (d), uncertainty in firn air content (e), surface velocity (f), change rate of ice-equivalent thickness (g) and uncertainty in change rate of ice-equivalent thickness (h) for GL0, FG1 and FG2 flux gates. The $y$ axis is the percentage of flux nodes that fall within each histogram bin.

See Appendix A for the calculation of the expected vertical gradient in ice velocity. One known issue is the systematic underestimation of ice flux with the coarsening of the resolution of the basal topography and/or the surface velocity (Fig. 5). This happens because fast-moving ice is concentrated in basal troughs: higher velocities multiplied by larger ice thickness and lower velocities multiplied by smaller ice thickness do not equate to average thickness multiplied by average velocity. FG2, which follows high-resolution RES profiles around almost the entire continent at the expense of proximity to the grounding line, provides the cross-sectional area with the lowest uncertainty and is most appropriate for estimating the total discharge, even after having to account for additional mass input between the gate and the grounding line. FG1 strikes a balance between proximity to the grounding line (GL0) and the distance from ice thickness observations. This gate is best suited for estimating changes in ice discharge. Our best estimate of total discharge is computed using the 2015 error-weighted average auto-RIFT velocities, FG2 and an estimate of additional mass flux between FG2 and GL0. We then compute the change in discharge between the 2015 and 2008 period at FG1 and subtract this from our best estimate of total discharge, accounting for dynamic volume change and changes in ice thickness between periods.

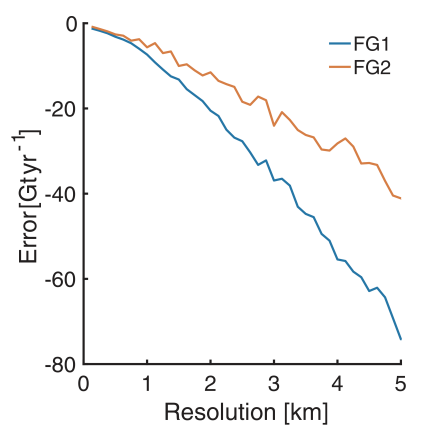

Figure 5. Error in total Antarctic discharge (relative to best estimate) when velocity and ice thickness are averaged for increasing along-flux-gate resolutions prior to computing flux.

This multi-flux-gate approach greatly reduces errors in estimates of ice discharge.

For areas south of the Landsat observation limit, we first calculate the total flux across gates located $>82.4^{\circ} \mathrm{S}$ using the 1997 and 2009 SAR velocity mappings of Scheuchl et al. (2012). To determine a representative 2015 flux rate we extrapolate the 2009 estimate assuming the same rate of change in discharge as observed for the 1997-2009 period.

Changes in flux $(\mathrm{d} F)$ were calculated at all flux-gate nodes (i) where both velocity mappings were valid and assumed to be unchanged elsewhere. In our analysis of velocities we found that there were some geocoding issues between the SAR (Rignot et al., 2011a) and Landsat velocities, which are most likely due to errors in the elevation model used to convert from radar slant range coordinates to a location on the Earth surface. We also found the SAR velocities unreliable for most of the northwest Antarctic Peninsula, where velocities near the grounding lines of narrow outlet glaciers were unrealistically low and likely the results of interpolation to areas of missing data. To minimize the impact of these artifacts in our flux-change analyses, we prescribed areas of zero change in flux along shear margins where changes are expected to be small and for much of the northwest Antarctic Peninsula (Fig. 2). Any residual geocoding errors are expected to introduce noise into our analysis but are unlikely to significantly bias our estimates of flux or flux change as errors will somewhat cancel when integrated across the entire glacier cross section (errors are typically of similar magnitude but opposite sign along right and left flow margins). See Appendix A for a comprehensive discussion of the uncertainty quantification.

One known limitation of our analysis is that the SAR velocity mosaic (Rignot et al., 2011a) that we difference our Landsat velocities with is derived from data spanning the period 1996-2009 with no information provided on the effective date of the data. We assume that the SAR mosaic has a representative date of circa 2008 as most data used in the mosaic was collected between 2007 and 2009. This data has been used previously to estimate total Antarctic dis- 
charge in Rignot et al. (2013) with a reference date of 2007 to 2008 and in Depoorter et al. (2013) with a reference date of 2007 to 2009. Individual year composites of the data used in older mosaic were recently made available (Mouginot et al., 2017). These new data come with more precise time stamps but at the expense of reduced horizontal resolution $(1 \mathrm{~km}$ vs. $450 \mathrm{~m}$ ), reduced spatial coverage and larger uncertainties. To ensure that our stated time period of circa 2008 is appropriate we resample (linear interpolation) the original SAR velocity mosaic to $1 \mathrm{~km}$ and compare to the error averaged 2007-2008 and 2008-2009 velocities from the new data set. Differences in flux across the FG1 are less than $2 \mathrm{Gt} \mathrm{yr}^{-1}$ for all basins except for basins $12,13,14$ and 24 that differ by $-4,-5,-6$ and $4 \mathrm{Gt} \mathrm{yr}^{-1}$, respectively. Some of the difference can be attributed to real differences in flow but also from differences in uncertainties between products (the original SAR mosaic having lower errors, particularly for the East Antarctic) and from differences in horizontal resolution. From this analysis we concluded that the best estimate of flux for the $\sim 2008$ period is produced by the earlier mosaic that has higher spatial resolution and the lower uncertainty, which is derived from the same underlying data contained in the annual mosaics. We also determine the period "circa 2008" characterizes well the effective date of the earlier SAR mosaic.

\subsection{Surface mass budget}

Here we estimate SMB for the 2008-2015 period from Regional Atmospheric Climate Model version 2.3 (RACMO2.3) output at a horizontal resolution of $5.5 \mathrm{~km}$ for the Antarctic Peninsula (van Wessem et al., 2016) and $27 \mathrm{~km}$ elsewhere (van Wessem et al., 2014). In RACMO2.3, SMB is calculated as the total precipitation (from snow and rain) minus total sublimation (directly from the surface and from drifting snow), wind-driven snow erosion and meltwater runoff. For the six Antarctic Peninsula basins (B1, B23-27), entirely or partially covered by the high-resolution model, we use the $27 \mathrm{~km}$ model output for the missing years of 2014 and 2015. For these basins, the $27 \mathrm{~km}$ model output was scaled to better agree with the $5.5 \mathrm{~km}$ output using the delta scaling approach. Uncertainty in SMB is taken to be $20 \%$ and is treated as uncorrelated between basins. The reader is referred to the works of van Wessem et al. (2014 and 2016) for a thorough discussion of the model setup, model validation and SMB uncertainties.

\subsection{Firn air content}

To convert volume fluxes to mass fluxes, the depth-averaged ice-sheet density is needed. FAC is a measure of the residual column that would remain if the firn column were compressed to the density of glacier ice, assumed to be $917 \mathrm{~kg} \mathrm{~m}^{-3}$. We estimate FAC using the firn densification model IMAU-FDM (Ligtenberg et al., 2011, 2014). IMAUFDM simulates firn densification by dry compaction and through meltwater processes (percolation, retention and refreezing) and is forced at the surface by 3-hourly resolution output of RACMO2.3 (van Wessem et al., 2016, 2014): surface temperature, $10 \mathrm{~m}$ wind speed, precipitation (solid and liquid), sublimation, wind-driven snow erosion/deposition and surface melt. The simulation over the entire Antarctic continent (at $27 \mathrm{~km}$ grid resolution) covers 1979-2015, while the Antarctic Peninsula simulation (at $5.5 \mathrm{~km}$ grid resolution) only covers 1979-2013. Both simulations output FAC at 2-day temporal resolution. The IMAU-FDM is calibrated using 48 depth-density observations from across Antarctica (Ligtenberg et al., 2011), and results have been successfully used to convert satellite altimetry (e.g., Gardner et al., 2013; Scambos et al., 2014; Shepherd et al., 2012) and ice thickness measurements (e.g., Depoorter et al., 2013; Fretwell et al., 2013) into estimates of ice mass change and iceequivalent thickness. Although time-evolving FAC is simulated throughout 1979-2015, we use the climatological average FAC as the most robust correction of our flux-gate thicknesses that are based on source data from many different times, sometimes unknown.

Uncertainties in the simulated FAC originate from either the observations used in the IMAU-FDM calibration process or the RACMO2.3 forcing data. This has been quantified at $10 \%$ (Supplement of Depoorter et al., 2013), composed of measurements errors in the observations of the pinning points in a depth-density profile: surface density, depth of $550 \mathrm{~kg} \mathrm{~m}^{-3}$ level and depth of $830 \mathrm{~kg} \mathrm{~m}^{-3}$ level. The RACMO2.3 uncertainty is primarily caused by the assumption used for model initialization; to initialize the IMAUFDM, it is assumed that the climate over the past 1001000 years was equal to the 1979-2013/15 average climate (Ligtenberg et al., 2011). Therefore, errors in the climatic forcing during the initialization period have a direct effect on the simulated firn density profile and subsequent FAC. Using sensitivity simulations, it was found that a $1 \%$ perturbation in accumulation during the initialization period causes a $0.75 \%$ error in FAC. Similarly, a $1 \%$ perturbation in the melt / accumulation ratio results in a $0.27 \mathrm{~m}$ error in FAC. The melt/accumulation ratio was used instead of the total melt, as the amount of annual snow that melts away in summer (i.e., the ratio between annual melt and annual accumulation) mainly determines how much firn pore space remains rather than the total amount of melt.

Along the ice-sheet grounding line the mean and standard deviation of FAC are $16.3 \pm 6.1 \mathrm{~m}$ with associated uncertainties of $3.7 \pm 1.0 \mathrm{~m}$. The combined uncertainties of the firn observations and the RACMO2.3 forcing of accumulation and surface melt showed the highest uncertainties on the western side of the Antarctic Peninsula, where high accumulation is combined with high melt. In areas where the modeled FAC uncertainty was higher than the actual FAC, the uncertainty was re-set to the same value as the FAC. 


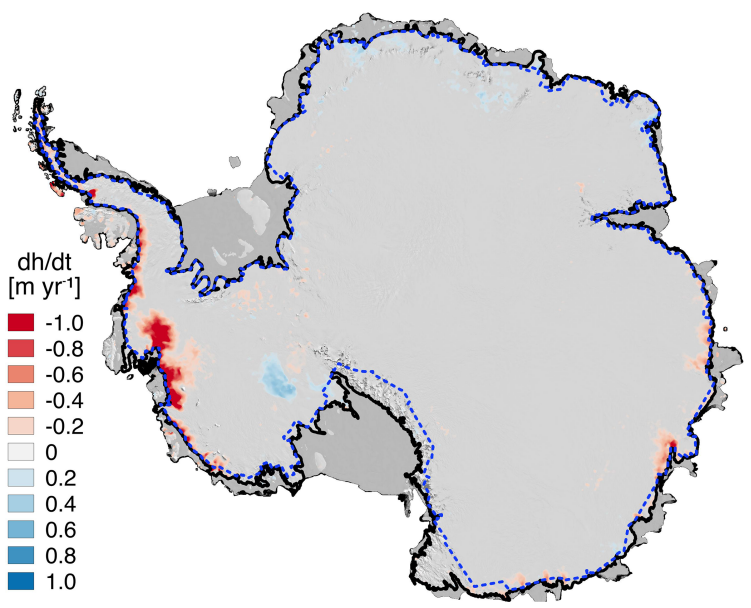

Figure 6. Surface elevation change for the period 2011 to 2015. Flux gate FG2 shown with blue dashed line and GL0 shown with heavy black line.

\subsection{Surface elevation and elevation change}

To account for thickness changes between the times of discharge calculation (2008 and 2015) and to correct for dynamic volume change between the flux gate and the grounding line, we use surface elevation rates estimated from CryoSat-2 radar altimetry between January 2011 and January 2015 (Fig. 6). CryoSat-2 elevations were derived from the ESA L1c product using the methodology developed by Nilsson et al. (2016). For each CryoSat-2 observation mode (LARM and SARIn), the derived surface elevations were separated into grounded and floating ice using the grounded and floating ice definitions from Depoorter et al. (2013) gridded to a $240 \mathrm{~m}$ in stereographic (EPSG: 3031) projection. Geophysical range corrections were applied to all data according to Bouzinac (2015). For floating ice, the tidal corrections (ocean tide and ocean loading) were replaced with values generated from the CATS2008 tidal model (Padman et al., 2008).

Surface elevation changes and rates of acceleration were generated using the surface fit method, described in Nilsson et al. (2016), onto a $1 \mathrm{~km}$ polar-stereographic grid (EPSG: 3031) for each mode. The derived elevation change distribution was edited to remove solutions with a magnitude larger than $\pm 15 \mathrm{~m} \mathrm{yr}^{-1}$, similar to the approach taken by Wouters et al. (2015). The edited data was then interpolated onto a $1 \mathrm{~km}$ grid using the weighted average of the 16 closest grid points, weighted by their standard error from the least-squares solution and distance. The standard error of the rate of change is assumed to be indicative of the formal error of each measurement. No correction for potential trends in FAC and glacial isostatic adjustment are applied, which may cause surface elevation rates to deviate from ice-equivalent thickness rates.

\subsection{Mass budget}

To assess the net ice sheet mass budget during the 20082015 period, we combine our new estimates of discharge (Sect. 2.3) with estimates of surface mass budget (Sect. 2.4) and basal melt rates (Pattyn, 2010; Van Liefferinge and Pattyn, 2013). Discharge and surface mass budget for the northern Antarctic Peninsula (B25-26) are highly uncertain and only included for reference in Table 2. The complex basal topography, narrow glacial valleys and highly crevassed ice, make interpretation of the bed reflection in radar data difficult in this region. Estimating the surface mass budget is equally challenging with large interannual variability and steep spatial gradients in both precipitation and melt due to extreme surface topography over a large latitudinal range. For B2526 , we therefore rely on net mass budgets determined from glacier elevation changes within the 2003-2011 period that we update with estimated discharge changes for 2008-2015 (Scambos et al., 2014; Berthier et al., 2012; Shuman et al., 2017). A full discussion of the updated Antarctic Peninsula mass budget estimate is provided in Appendix B.

\section{Results}

\subsection{Changes in surface velocity and ice discharge}

By combining uncertainties of ice velocity and its relation to depth-averaged velocity, ice thickness, dynamic volume change and SMB for each flux-gate configuration, we estimate a total discharge uncertainty of $5.6 \%$ for GL0, $4.5 \%$ for FG1 and $2.1 \%$ for FG2. The lower uncertainty for FG2 is due to the extensive use of RES data for ice thickness along the flux gate (Fig. 4). Hence, we use FG2 in combination with the Landsat velocity field to estimate total discharge. Obtaining continent-wide discharge for $\sim 2008$ using the SARbased velocity field (Rignot et al., 2011a) at the FG2 flux gate is not possible due to data gaps inland of the grounding line. Instead, we estimate discharge change between the 2008 and Landsat mappings at FG1 and then subtract that from the Landsat estimate of discharge to obtain a total estimate for 2008. This approach reduces the impact of ice thickness errors at FG1 since they get scaled by velocity differences rather than by velocity magnitudes that are typically much larger. Thickness changes at FG1 and changes in the rate of dynamic volume change between FG1 and the grounding line occurring between 2008 and Landsat mappings were accounted for in the estimates of discharge change using the derived CryoSat-2 elevation change rates for 2011-2015 (see Sect. 2.6). Rates of volume change in 2008 and 2015 were extrapolated using the measured acceleration over the 20112015 period. Calculating flux in this way reduced the uncertainty in the total flux estimate generated from SAR velocities from $99 \mathrm{Gt} \mathrm{yr}^{-1}$ when calculating total discharge only at 
Table 2. Surface area, cross sectional area for flux gate FG2, discharge corrected for dynamic volume change and surface mass balance between flux gate FG2 and the grounding line, basal melting, surface mass balance (SMB) and net mass balance for the 27 basins defined by Zwally et al. (2002). Cumulative numbers are provided for the East Antarctic Ice Sheet (EAIS: B2-17), the West Antarctic Ice Sheet (WAIS: B1, B18-23) and the Antarctic Peninsula (AP: B24-B27). Basal melt rates are from Van Liefferinge and Pattyn (2013) and calculated according to Pattyn (2010). SMB is calculated using the RACMO2.3 regional climate model at $5.5 \mathrm{~km}$ (van Wessem et al., 2016) resolution over the Antarctic Peninsula and $27 \mathrm{~km}$ elsewhere (van Wessem et al., 2014) and averaged over the 2008-2015 period. The net mass balance is calculated as the 2008-2015 SMB minus the average rate of discharge minus basal melt. Discharge for 2008 is derived from Rignot et al. (2011a) and for 2015 from the mean of the JPL 2015 error-weighted Landsat velocity mapping.

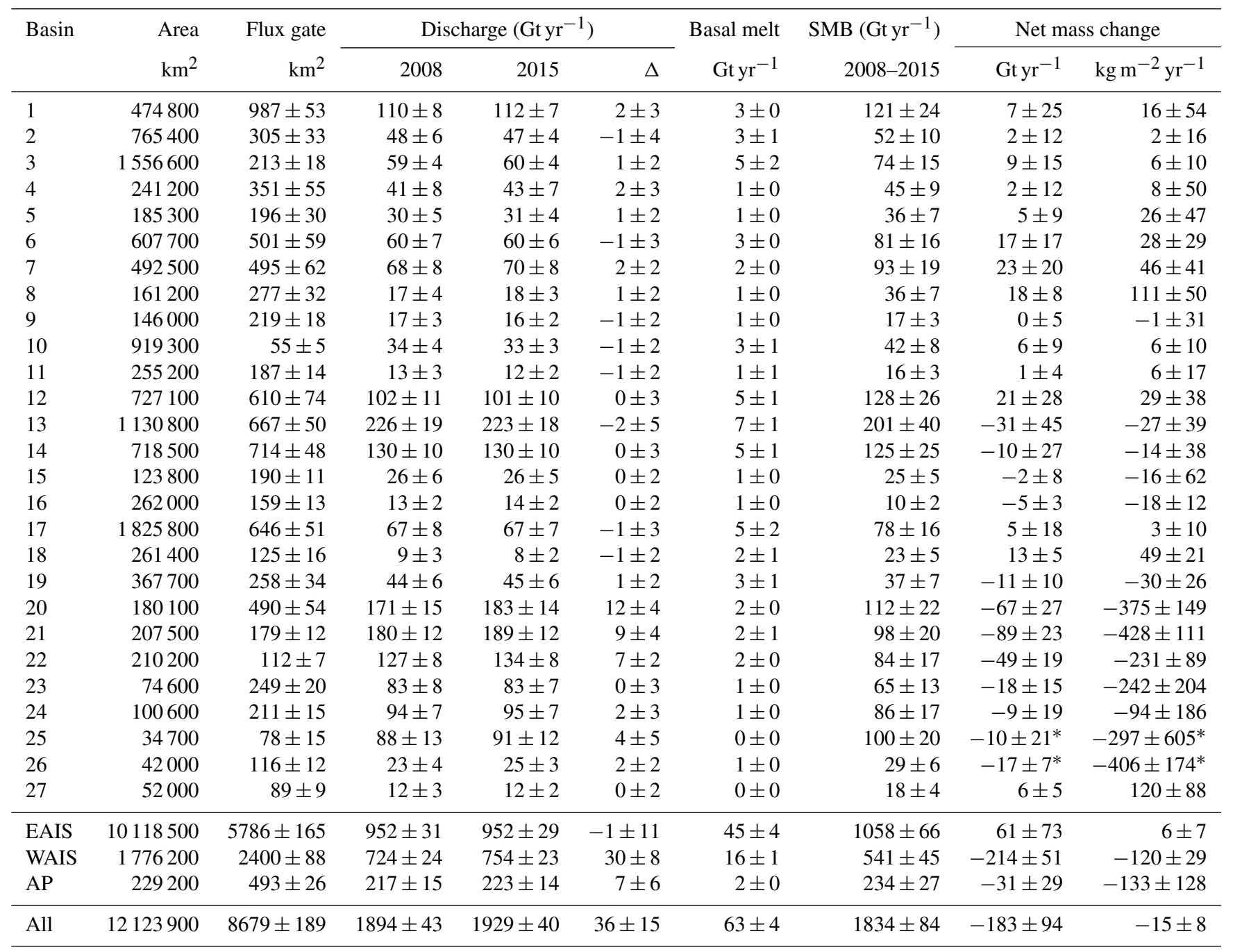

* Net mass balance for the northern Antarctic Peninsula (basins 25 and 26) is not determined using calculated discharge and SMB because of large and poorly constrained uncertainties in ice thickness and modeled SMB. Instead the net mass balance for basins 25 and 26 are determined by updating the mass balance estimate of Scambos et al. (2014) with changes in discharge determined here (see Appendix B).

the grounding line to $40 \mathrm{Gt} \mathrm{yr}^{-1}$, a $60 \%$ reduction in uncertainty, when applying this combined approach .

Comparing differences in discharge estimates between 6 Landsat velocity mappings (Fig. 7, 4 auto-RIFT v0.1, 2 LISA v1.0) shows good agreement despite differences in feature tracking methodologies, template chip size, horizontal resolution and time periods. The standard deviations between flux-change estimates are below the stated uncertainty in discharge listed in Table 2 for all 27 basins. Differences that do exist can be attributed to product errors. Auto-RIFT W15 has the lowest uncertainties, followed by auto-RIFT M15 then auto-RIFT W14 and M14 with the LISA 125 and $750 \mathrm{~m}$ products having the highest uncertainties (See Fig. A1). auto-RIFT uncertainties are lowest for the 2015 mapping simply due to a much larger number of available image pairs. The reason for higher uncertainties of the LISA products is not entirely known but is likely due to differences in geolocation offset correction and merging proce- 




Figure 7. Change in flux across FG1 flux gate (shown with green line; see Methods) for the 27 basins defined by Zwally et al. (2002) calculated by differencing the pan-Antarctic SAR mapping of Rignot et al. (2011a, circa 2008) with six different Landsat 8 velocity mappings (M14/15 = JPL median of all 2014/15 image pairs; W14/15 = JPL weighted average of all 2014/15 image pairs; L750 = NSIDC 750 $\mathrm{m}$ average of all 2014-2015 image pairs; L125 = NSIDC $125 \mathrm{~m}$ average of all 2014-2015 image pairs). Basins 2, 17 and 18 are complimented with differences in 1997 and 2009 SAR velocities poleward of $82.5^{\circ} \mathrm{S}$ (Scheuchl et al., 2012). Much of the difference between velocity mappings can be attributed to product errors. W15 has the lowest uncertainties (used in this study), followed by M15, then W14 and M14, with the LISA products having the highest uncertainties (See Fig. A1).

dures. Some difference between mappings can also be expected due to real changes in ice flow between effective dates. This good agreement between products gives us confidence that our results are not sensitive to the Landsat processing methodology. From here forward we only present results generated using auto-RIFT W15 that provides the lowest uncertainties and longest period over which change in discharge is calculated.

\subsubsection{Amundsen Sea}

For the B21 and B22 catchments, containing Pine Island, Thwaites, Haynes, Pope, Smith and Kohler glaciers (Fig. 8), we find a $6 \%$ increase in ice discharge or $17 \pm 4 \mathrm{Gt} \mathrm{yr}^{-1}$ (Table 2). This implies an average discharge increase of $2.4 \mathrm{Gt} \mathrm{yr}^{-2}$ for 2008-2015 that is considerably lower than the $6.5 \mathrm{Gt} \mathrm{yr}^{-2}$ previously estimated for 1994-2008 (Mouginot et al., 2014). This recent slowing in the rate of acceleration is in excellent agreement with the previously published temporally dense history of ice discharge that gave a rate of discharge increase for this region of $2.3 \mathrm{Gt} \mathrm{yr}^{-2}$ for overlapping but shorter period of 2010-2013 period (Mouginot et al., 2014). Pine Island and Thwaites glaciers both show clear signs of persistent dynamic drawdown, with velocities increasing by $>100 \mathrm{~m} \mathrm{yr}^{-1}$ up to $80-100 \mathrm{~km}$ inland from the grounding line (Fig. 9). Figure 9 shows a peak in Pine Island velocity change at $50 \mathrm{~km}$ and a secondary peak at $110 \mathrm{~km}$ upstream of the grounding line. We see no such peak when comparing between Landsat products, which makes us confident that the secondary peak is not an artifact of the Landsat processing. One possible non-geophysical explanation is that the radar mosaic includes data from a period significantly earlier than 2008 for area of the second peak. East Kohler and Smith glaciers also show extensive speedups throughout their length, with increases of $>100 \mathrm{~m} \mathrm{yr}^{-1}$ reaching more than $40 \mathrm{~km}$ inland likely driven by increased ocean melt rates and subsequent grounding-line retreat (Khazendar et al., 2016; Scheuchl et al., 2016). Patterns of velocity change for Pope and Kohler glaciers are more complex, with slowing of up to $100 \mathrm{~m} \mathrm{yr}^{-1}$ near the grounding line and increased speed by $\sim 50 \mathrm{~m} \mathrm{yr}^{-1}$ upstream reaching $40-80 \mathrm{~km}$ inland. This pattern of change is suggestive of an earlier period of dynamic drawdown that is slowly propagating inland contrasted by more recent deceleration near the grounding line. Glaciers feeding the Getz and Sulzberger ice shelves (B20; including Berry, Hull and Land glaciers) increased in speed by 10 to 


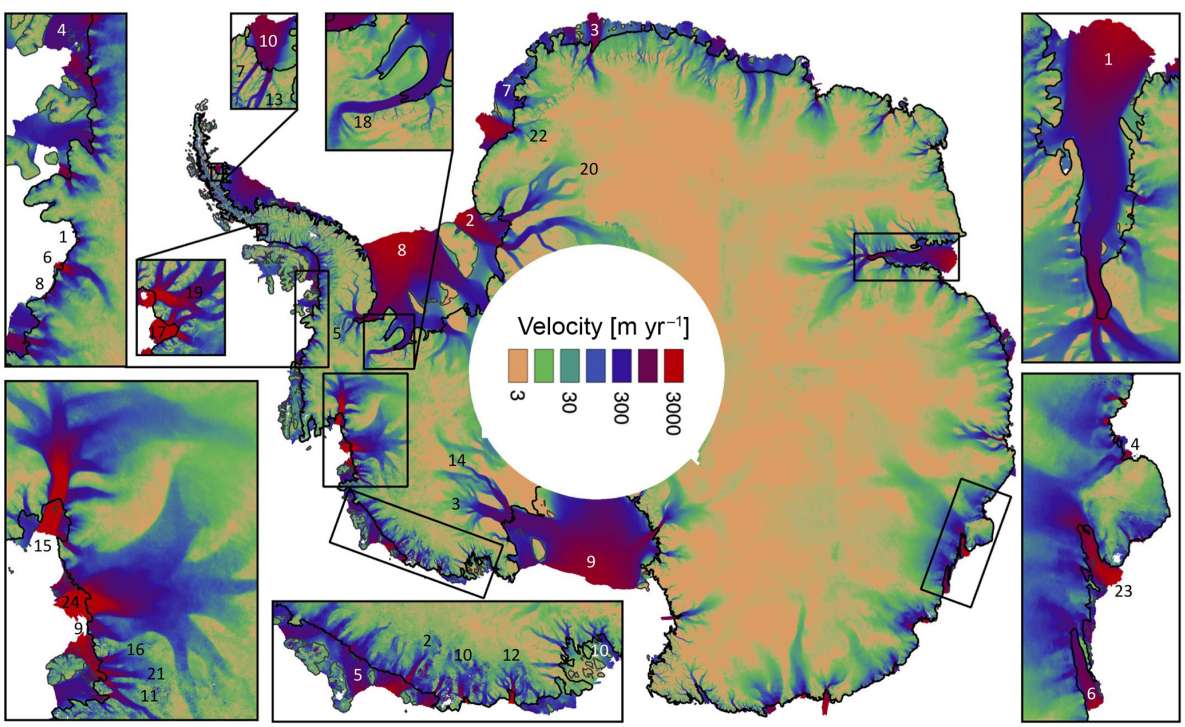

Figure 8. 2015 Antarctic ice sheet surface velocities shown in log scale determined from feature tracking of $>200000$ Landsat image pairs. Glacier and ice streams discussed in text labeled with black numbering: (1) Alison, (2) Berry, (3) Bindschadler, (4) Bond, (5) Evans, (6) Ferrigno, (7) Flask, (8) Fox, (9) Haynes, (10) Hull, (11) Kohler, (12) Land, (13) Leppard, (14) MacAyeal, (15) Pine Island, (16) Pope, (17) Prospect, (18) Rutford, (19) Seller, (20) Slessor, (21) Smith, (22) Stancomb-Wills, (23) Totten, and (24) Twaites. Ice shelves labeled with white numbering: (1) Amery, (2) Filchner, (3) Fimbul, (4) George VI, (5) Getz, (6) Moscow U., (7) Riiser-Larsen, (8) Ronne, (9) Ross, (10) Scar Inlet, and (10) Sulzberger.

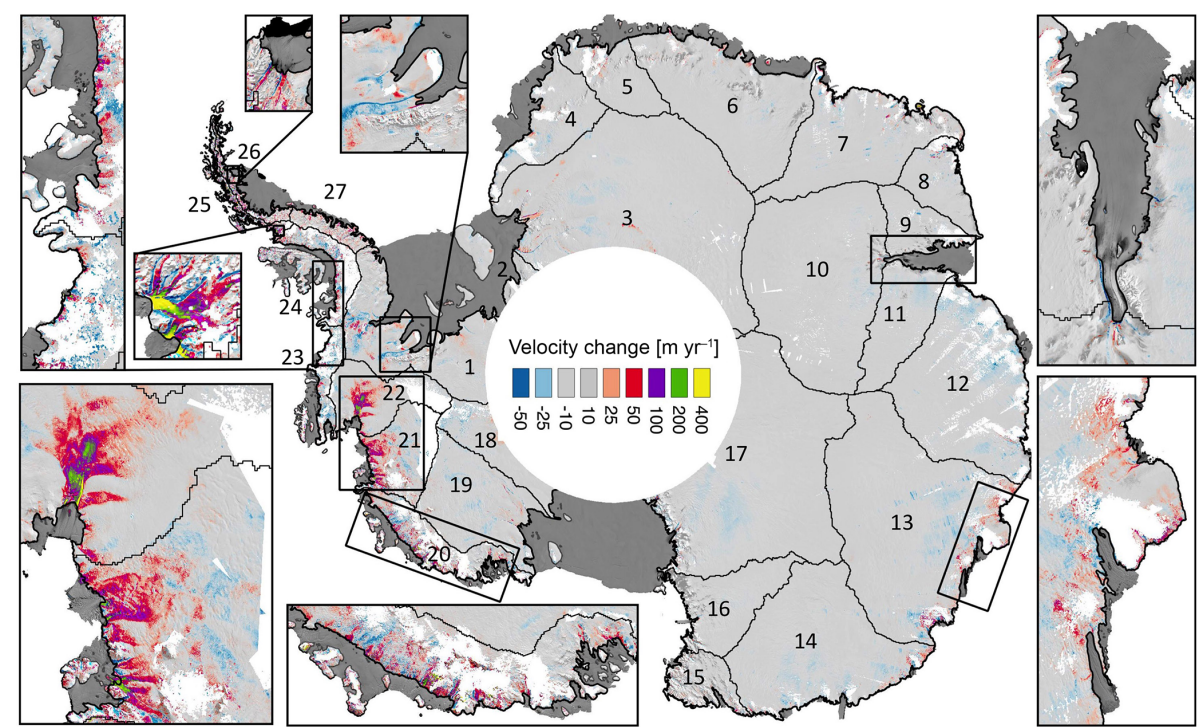

Figure 9. Change in surface velocities between date of pan-Antarctic SAR mapping (Rignot et al., 2011a, circa 2008) and new 2015 velocity mapping produced here from feature tracking of Landsat 8 imagery. Change in velocities shown for grounded ice only. Missing data shown in white and the 27 basin boundaries defined by Zwally et al. (2002) are shown in black.

$100 \mathrm{~m} \mathrm{yr}^{-1}$ at their grounding lines, increasing discharge by $6 \%$ (Table 2). This result is in broad agreement with Chuter et al. (2017) that observed increases in ice velocity during the 2007-2013 period alongside 2010-2013 dynamic thinning rates of $0.7 \mathrm{~m} \mathrm{yr}^{-1}$ for the glaciers feeding the Abbot and Getz ice shelves.

\subsubsection{Bellingshausen coast}

Localized accelerations of 50-200 $\mathrm{m} \mathrm{yr}^{-1}$ are observed near grounding lines for several of the major glaciers along the Bellingshausen Coast (B23 and B24) including the Ferrigno, Fox and Alison ice streams and glaciers feeding into the southern George VI Ice Shelf. Despite some areas of flow 
acceleration, increases in discharge are highly localized. For many glaciers, the flux-gate cross section is decreasing from regional thinning, resulting in negligible changes in discharge. This result is unexpected, but with high confidence, as this region has experienced high rates of ice shelf thinning (Paolo et al., 2015) and grounding-line retreat (Christie et al., 2016), both of which were inferred to have resulted in accelerated dynamic thinning that contributed to a $56 \pm 8 \mathrm{Gt} \mathrm{yr}^{-1}$ increase in the rate of mass loss that began around 2009 and persisted until at least April 2014 (Wouters et al., 2015). From our analysis we conclude that any changes in discharge contributing to observed rates of thinning must have occurred prior to the SAR mapping of ice velocities. This result agrees with a recent investigation of longer-term (19952016) changes in ice discharge for this region (Hogg et al., 2017) that found that the region's glacier experienced an increase in ice discharge between 1995 and 2008 and almost no change in discharge between 2008 and 2016.

\subsubsection{Northern Antarctic Peninsula}

Along the west coast of the northern Antarctic Peninsula (B25) glaciers feeding into Marguerite Bay (Seller and Prospect) sped up by $400-800 \mathrm{~m} \mathrm{yr}^{-1}$ at their grounding lines, the largest speedup of all Antarctic glaciers, with an increase of $>100 \mathrm{~m} \mathrm{yr}^{-1}$ reaching $10-15 \mathrm{~km}$ upstream. This speedup was recently attributed to increased ocean melt rates resulting from SOI/ENSO-driven ocean warming (Walker and Gardner, 2017). The majority of the west-coast glaciers to the north of Marguerite Bay are not sufficiently sampled in the earlier SAR mapping and are assumed to be unchanged between 2008 and 2015 (Fig. 2). Along the east coast of the northern Antarctic Peninsula (B26) most glaciers feeding into the former Larsen A and B ice shelves that collapsed in 1995 and 2002, respectively, either have not changed significantly or show signs of slowing near their grounding lines (Wuite et al., 2015), with the exception of Leppard and Flask glaciers. These two glaciers have sped up by $50-100 \mathrm{~m} \mathrm{yr}^{-1}$ at their grounding lines, likely in response to reduced ice shelf buttressing and a resulting speedup of the abutting Scar Inlet Ice Shelf (Khazendar et al., 2015). Overall, this region shows a modest increase in ice discharge of $6 \pm 6 \mathrm{Gt} \mathrm{yr}^{-1}$, most of which comes from the glaciers flowing into Marguerite Bay. Small changes in rates of discharge between periods are in good agreement with constant rates of RACMOderived surface mass budget and mass changes derived from GRACE data (Appendix B).

\subsubsection{Ice streams feeding large ice shelves}

Our analysis suggests a $5-20 \mathrm{~m} \mathrm{yr}^{-1}$ slowdown of a broad region upstream of both Bindschadler and MacAyeal ice streams, which feed the Ross Ice Shelf. Ice streams feeding the Ronne-Filchner Ice Shelf show heterogeneous changes with slowing of $15-40 \mathrm{~m} \mathrm{yr}^{-1}$ upstream of the Rutford and
Evans ice stream grounding lines and $\sim 20 \mathrm{~m} \mathrm{yr}^{-1}$ speedup of the Slessor Ice Stream. Slowing in the Rutford Ice Stream is consistent with the slowing observed between 1997 and 2009 (Scheuchl et al., 2012), but the apparent increase in velocity of the Slessor Ice Stream is of equal magnitude but of opposite sign to the changes observed between 1997 and 2009 (Scheuchl et al., 2012). Further to the east, the Stancomb-Wills Glacier increased in speed by $20-40 \mathrm{~m} \mathrm{yr}^{-1}$, just upstream of the grounding line, with glaciers feeding the Riiser-Larsen, Fimbul and Amery ice shelves showing little change. Overall, changes in surface velocity along grounding lines of ice streams and glaciers feeding the major ice shelves of East and West Antarctica have not been large enough to significantly impact the net ice discharge for their respective basins (Table 2).

\subsubsection{East Antarctic glaciers}

Ice discharge has remained remarkably steady for the East Antarctic glaciers, particularly along the coasts of Dronning Maud Land and Enderby Land. These basins (B5-B8) showed very little change in ice discharge. The region to the west of Law Dome, including Underwood and Bond glaciers, shows subtle evidence of some increased flow speed and ice discharge, though the signal is near the limit of detection in part due to larger errors in the earlier radar mosaic for this region. However, the much larger Totten Glacier and the tributaries of the Moscow University Ice Shelf (B13) that drain a large fraction of the East Antarctic Ice Sheet show localized areas of ice speed variations but little change in discharge (Fig. 1). This result is consistent with recent findings of $\mathrm{Li}$ et al. (2016) showing that the Totten Glacier increased in velocity between 2001 and 2007, likely in response to elevated ocean temperature, but has been relatively unchanged since.

\subsubsection{Antarctic discharge}

In total we estimate that between the SAR and autoRIFT W15 velocity mappings, the Antarctic ice sheet increased its solid ice discharge to the ocean from $1894 \pm 43$ to $1929 \pm 40 \mathrm{Gt} \mathrm{yr}^{-1}$. This represents a $36 \pm 15 \mathrm{Gt} \mathrm{yr}^{-1}$ increase in total discharge between 2008 and 2015; $78 \%$ of the increases in discharge concentrated to glaciers flowing into the Amundsen Sea and another $10 \%$ coming from glaciers flowing into Marguerite Bay. Breaking it down to the main ice-sheet regions, the discharge of the West Antarctic Ice Sheet (B1, B18-23) increased by $30 \pm 8 \mathrm{Gt} \mathrm{yr}^{-1}$ and the Antarctic Peninsula (B24-27) by $7 \pm 6 \mathrm{Gt} \mathrm{yr}^{-1}$, representing a 4 and $3 \%$ increase in discharge, respectively. The discharge of the East Antarctic Ice Sheet (B2-17) was remarkably unchanged with a total discharge of $952 \pm 31$ and $952 \pm 29 \mathrm{Gt} \mathrm{yr}^{-1}$ in 2008 and 2015, respectively.

Our estimate of 2008 total Antarctic ice discharge $\left(1894 \pm 43 \mathrm{yr}^{-1}\right)$ is smaller than earlier estimates of $2048 \pm 146$ and $2049 \pm 86 \mathrm{Gt} \mathrm{yr}^{-1}$ by Rignot et al. (2013) 
and Depoorter et al. (2013), respectively. Both earlier studies use the same SAR velocity mosaic as used here (Rignot et al., 2011a). Our estimate agrees with that of Rignot et al. (2013) within stated errors but not with that of Depoorter et al. (2013). Rignot et al. (2013) used Operation Ice Bridge and BEDMAP-2 ice thickness data at InSAR derived grounding lines to determine a total Antarctic discharge, with upscaling accounting for $352 \mathrm{Gt} \mathrm{yr}^{-1}$ of the total discharge. The most obvious reason for the difference in the central estimates is the definition of the flux gates. Rignot et al. (2013) mostly rely on BEDMAP-2 data while our study draws almost entirely from flight data. Another possible reason for the difference is the upscaling of results for unmeasured basins. For these basins the total discharge is assumed to be the modeled climatological average surface mass balance integrated over the upstream basin. Such estimates have not been adjusted for losses due to basal melt, and they are sensitive to errors in the modeled SMB and to the delineation of the contributing basin area over which SMB is integrated. Upscaling for unmeasured areas by Depoorter et al. (2013) accounted for $476 \mathrm{Gt} \mathrm{yr}^{-1}$ of their estimated discharge. The Depoorter et al. (2013) study uses a different definition of groundling but otherwise uses the same data as used in Rignot et al. (2013). Again, much of the difference between estimates can be attributed to the definition of ice thickness and upscaling to unmeasured basins. It should also be noted that Depoorter et al. (2013) and Rignot et al. (2013) both used output from an earlier version of RACMO that produced larger total SMB than the version of the model used in our study. Since SMB is used to upscale discharge, this likely contributes some to the larger discharge estimates. Similar conclusions were made for updated Greenland Ice Sheet discharge estimates that were lower than previous estimates (Enderlin et al., 2014).

\subsection{Changes in net mass balance}

For the West Antarctic Ice Sheet, the 2008-2015 net mass budgets were negative for all but two basins (B1 and B18) (Fig. 10), summing to a total imbalance of $-214 \pm 51 \mathrm{Gt} \mathrm{yr}^{-1}$ with largest rates of loss collocated with increased glacier velocities along the Amundsen Sea Embayment (B21 and B22) and Getz Ice Shelf (B20). The large mass loss for the Getz Ice Shelf region is in contrast to the near balance conditions recently reported by Chuter et al. (2017) for the 2006-2008 period but is in agreement with the 2010-2013 estimate of net mass change by MartínEspañol et al. (2016). The East Antarctic Ice Sheet is found to have increased slightly in mass at a rate of $61 \pm 73 \mathrm{Gt} \mathrm{yr}^{-1}$ with largest gains in Dronning Maud (B6) and Enderby Land (B7 and B8) that can be partially attributed to increase in precipitation rate $\left(+28 \mathrm{Gt} \mathrm{yr}^{-1}\right.$ relative to $1979-2007$ mean) during the study period, which is consistent with earlier findings (Boening et al., 2012; King et al., 2012; Shepherd et al., 2012). For the whole of Antarctica, we esti- mate an average mass budget of $-183 \pm 94 \mathrm{Gt} \mathrm{yr}^{-1}$ for the 2008-2015 period. Other recent estimates of Antarctic mass change include those derived from CryoSat-2 altimetry of $-159 \pm 48 \mathrm{Gt} \mathrm{yr}^{-1}$ for the period 2010-2013 (McMillan et al., 2014) and $-116 \pm 76 \mathrm{Gt} \mathrm{yr}^{-1}$ for the period 2011-2014 (Helm et al., 2014, assuming density of ice) and a recent estimate from the joint inversion of gravity, altimetry and GPS data of $-159 \pm 22 \mathrm{Gt} \mathrm{yr}^{-1}$ for the period 2010-2013 (Martín-Español et al., 2016). All three studies show near balance to slightly positive mass changes for the East Antarctic Ice Sheet and large losses for the West Antarctic Ice Sheet and the Antarctic Peninsula, all of which agree well with the results presented here when considering uncertainties and differences in study periods.

\section{Discussion}

Areas of accelerated surface velocity (Fig. 9) and increased ice discharge are in good agreement with basin-scale assessment of changes in ice flow and ice discharge (Li et al., 2016; Mouginot et al., 2014) and with patterns of ice sheet thinning determined from laser and radar altimetry (Flament and Rémy, 2012; Helm et al., 2014; Pritchard et al., 2009). These show broad regions of surface lowering for glaciers feeding into the Amundsen Sea Embayment and Getz Ice Shelf and rapid drawdown of smaller glacier systems in the Antarctic Peninsula. Glaciers and ice streams feeding major ice shelves were remarkably steady with small heterogeneous changes in velocity. Apparent upstream slowing of Bindschadler and MacAyeal ice streams are at the limit of detectability and difficult to interpret. Recent assessments show varying changes in ice stream velocities for this region (Hulbe et al., 2016; Scheuchl et al., 2012), suggesting that measured trends may be influenced by rapid changes in the sub-ice-stream hydrology (Hulbe et al., 2016).

Strongly negative net mass budgets are apparent for the West Antarctic Ice Sheet and are largely due to mean rates of ice discharge greatly exceeding rates of snow accumulation. The basin-averaged results (Fig. 10) match remarkably well with patterns of pan-Antarctic multi-decadal (1994-2012) changes in ice shelf thickness (Paolo et al., 2015): high rates of mass loss from glaciers feeding into the Amundsen Sea are collocated with high rates of ice shelf thinning and near balance conditions for Wilkes Land glaciers and basins feeding the Filchner-Ronne, Ross and Amery ice shelves are collocated with ice shelves that have experienced little change in ice thickness over the past two decades. This result further supports the strong link between oceanic melting of ice shelves and ice sheet mass budget (Pritchard et al., 2012).

The link between basin mass budget and change in discharge is less obvious. This is primarily due to differences in representative periods as mass budgets represent the cumulative imbalance away from equilibrium state while changes in discharge are only representative of change in discharge 


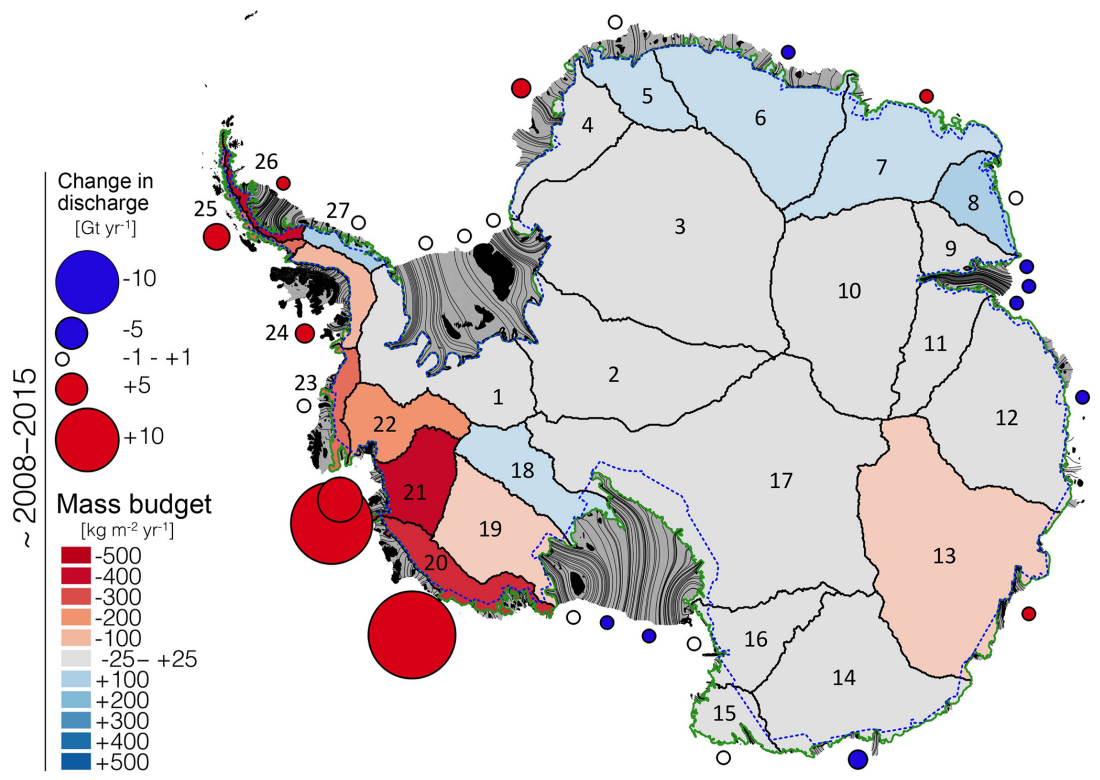

Figure 10. Mass budget and change in discharge for the 27 basins defined by Zwally et al. (2002). Mass budget is calculated as described in Table 2 using 2008-2015 average surface mass balance. Change in discharges (circles) calculated by differencing the pan-Antarctic SAR mapping of Rignot et al. (2011a; circa 2008) with weighted average of all 2015 image-pair displacements supplemented with 2009 SAR velocities to fill missing Landsat coverage poleward of $82.5^{\circ} \mathrm{S}$ (Scheuchl et al., 2012) with a correction for acquisition time differences to provide an estimate of total discharge for the interior basins (2, 17 and 18; see Table 2). Flux gates FG1 and FG2 are shown with solid green and dashed blue lines, respectively.

between two periods in time; e.g., a glacier can decelerate but still be discharging ice at a rate that exceeds the surface mass budget minus basal melt. Increased ice discharge from the Amundsen Sea Embayment and subsequent partial re-stabilization have been attributed to changes in ice shelf buttressing (Jacobs et al., 1996; Macgregor et al., 2012) that resulted from increased ice shelf basal melt rates (Jacobs et al., 2011; Jenkins et al., 1997) and more recently to a decrease in ocean melting resulting from changes in the temperature of intermediate depth waters (Dutrieux et al., 2014). Increased discharge from glaciers feeding into the Getz Ice Shelf is likely in response to rapid thinning of the ice shelf due to changes in ocean circulation and the depth of warmer modified Circumpolar Deep Water (Jacobs et al., 2013).

\section{Conclusion}

Applying novel feature tracking methods to hundreds of thousands of Landsat image pairs we are now able construct a detailed and comprehensive record of recent changes in Antarctic-wide ice flow. When combined with optimized flux-gate definitions and an earlier mapping of surface velocity (Rignot et al., 2011a), such measurements allow for accurate reconstructions of ice discharge and changes in ice discharge through time. Applying these new capabilities, we determine that the Antarctic ice sheet discharged $1894 \pm 43 \mathrm{Gt} \mathrm{yr}^{-1}$ of solid ice into the ocean in 2008 , in- creasing to $1929 \pm 40 \mathrm{Gt} \mathrm{yr}^{-1}$ in 2015 with $78 \%$ of the increase in discharge concentrated to glaciers flowing into the Amundsen Sea and another $10 \%$ comes from glaciers flowing into Marguerite Bay. Glaciers and ice streams feeding major ice shelves were remarkably steady with small heterogeneous changes in velocity. Strongly negative net mass budgets are apparent for the West Antarctic Ice Sheet and are largely due to mean rates of ice discharge greatly exceeding rates of snow accumulation. The East Antarctic Ice Sheet experienced near-balance conditions with modest gains in Dronning Maud and Enderby Land driven by increased rates of precipitation.

Over the last decade, it is evident that larger-scale changes in discharge are relatively modest ( $<7 \%$ for all basins) compared to the fractional imbalance between discharge and surface mass budget (up to several tens of percent). This suggests that the recent pattern of mass loss in Antarctica, dominated by the Amundsen Sea sector, is likely a part of a longerterm phase of enhanced glacier flow initiated in the 1990s as indicated by satellite records (Konrad et al., 2017; Mouginot et al., 2014) or as early as the 1940s as proposed from subice-shelf sediment records (Smith et al., 2017).

Glaciology is rapidly transitioning from an observationally constrained environment to one with ample high-quality, high-volume satellite data sets suitable for mapping ice flow on continental scales (e.g., Landsat 8 , Sentinel 2a/b, Sentinel $1 \mathrm{a} / \mathrm{b}$ ). This study provides a foundation for continued assessment of ice sheet flow and discharge that will allow re- 
searches to observe both large and subtle changes ice sheet flow that may indicate early signs of ice sheet instability with low latency. Such a capability would help to diagnose unstable flow behavior and, in conjunction with high accuracy measurements of ice sheet elevation and mass change, would lead to improved assessment ice sheet surface mass balance and ice shelf melt rates. Low-latency monitoring of ice flow and discharge would also allow field programs, flight planning and satellite tasking to coordinate the collection of complimentary observations in areas of changing ice behavior. These advances will ultimately lead to a deeper understanding of the causal mechanisms resulting in observed and future ice sheet instabilities. Any substantial improvement in our assessment of ice sheet discharge will require more detailed knowledge of ice thickness just upstream of the grounding line, particularly for areas of complex flow such as the Antarctic Peninsula and Victoria Land. Errors in discharge estimates can be greatly reduced if thickness profiles are acquired perpendicular to ice flow. Improved estimates of net mass change calculated using the mass budget approach will come from continued refinement of regional climate models and better estimates of basal melt.

Data availability. All velocity mosaics, grounding lines, flux gates and ancillary data are available from the National Snow and Ice Data Center (Gardner et al., 2018a, b; Fahnestock et al., 2016). 


\section{Appendix A: Uncertainty quantification}

\section{A1 Ice discharge}

The uncertainty in flux estimates were calculated for each of the 27 basins as

$$
\begin{aligned}
\sigma F= & \sqrt{\sigma F_{H}^{2}+\sigma F_{\mathrm{d} H}^{2}+\sigma F_{V}^{2}+\sigma F_{\mathrm{SMB}}^{2}+\sigma F_{\mathrm{d} V_{\mathrm{dyn}} / \mathrm{d} t}+\sigma F_{\mathrm{bm}}^{2}} \\
& +\sigma F_{\bar{V}},
\end{aligned}
$$

where $\sigma F_{H}$ is due to uncertainties in ice-equivalent thickness, $\sigma F_{\mathrm{d} H}$ is due to uncertainties in the change of iceequivalent thickness between the measurement times of ice thickness and surface velocity, and $\sigma F_{V}$ is due to uncertainties in measured velocity. $\sigma F_{\bar{V}}$ is due to the assumption that the depth-averaged velocity $(\bar{V})$ is equal to the surface velocity and is added as a bias (outside of the quadrature sum) to both sides of the error envelope for simplicity. $\sigma F_{\mathrm{d} V_{\mathrm{dyn}}} / \mathrm{d} t$, $\sigma F_{\mathrm{SMB}}$ and $\sigma F_{\mathrm{bm}}$ are uncertainties introduced by dynamic volume change, surface mass balance and basal melt corrections applied between the flux gate and the true grounding

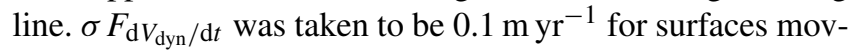
ing faster than $200 \mathrm{~m} \mathrm{yr}^{-1} . \sigma F_{\mathrm{SMB}}$ was taken to be $20 \%$ of the SMB. Uncertainties in flux resulting from uncertainties in ice thickness, changes in ice thickness and surface velocity were propagated assuming a conservative correlation length along the flux gate as follows:

$$
\begin{aligned}
& \sigma F_{H}=\sqrt{\sum_{1}^{n_{H}}\left(\sum_{i=1}^{m_{H}} \sigma H_{i} W_{i} V_{i}\right)^{2}} \\
& \sigma F_{\mathrm{d} H}=\sqrt{\sum_{1}^{n_{\mathrm{d} H}}\left(\sum_{i=1}^{m_{\mathrm{d} H}} \sigma \frac{\mathrm{d} H}{\mathrm{~d} t}{ }_{i} \mathrm{~d} t_{i} W_{i} V_{i}\right)^{2}}, \\
& \sigma F_{V}=\sqrt{\sum_{1}^{n_{V}}\left(\sum_{i=1}^{m_{V}} \sigma V_{i} W_{i} H_{i}\right)^{2}}+\sum_{i=1}^{\mathrm{nn}} \sigma V_{0 i} W_{i} H_{i},
\end{aligned}
$$

where $m$ is the number of point estimates of flux $(x)$ for each correlation length distance along the flux gate and $n$ is the number of discrete uncorrelated lengths for each basin for measurements of ice thickness $(H)$, changes in ice thickness $(\mathrm{d} H)$ and the surface velocity normal to the flux gate $(V)$. Uncertainties in ice thickness $\left(\sigma H_{i}\right)$ are taken as the RSS of the thickness estimate and the FAC. Uncertainties in changes in ice thickness $\left(\sigma \frac{\mathrm{d} H}{\mathrm{~d} t}\right)$ are determined as the RSS of uncertainty due to changes in FAC and surface elevation. $\mathrm{d} t$ is the difference in time between the measurement of ice thickness and the measurement of surface velocity. $\sigma F_{V}$ is modeled using a velocity uncertainty component $\sigma V_{0}$ that is fully correlated at lengths smaller than an estimated correlation length and uncorrelated at larger lengths $(\sigma V)$. Comparing Landsat and SAR velocities measured at flux-gate nodes for basins with minimal change in ice discharge (B1-19 and B27); i.e., where velocity differences are assumed to be indicative measurement uncertainty, we were able to model the observed
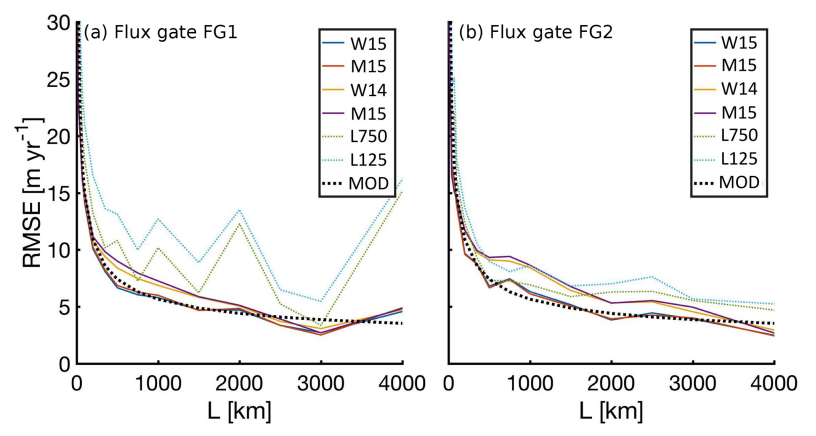

Figure A1. RMSE of the Landsat component of velocity that is normal to the flux-gate cross section at FG1 (a) and FG2 (b) flux nodes relative to $\sim 2008$ SAR velocities (Rignot et al., 2011a) as a function of averaging distance $(L)$. MOD is the modeled uncertainty assuming a fully correlated uncertainty of $1 \mathrm{~m} \mathrm{yr}^{-1}$ plus a $3 \mathrm{~m} \mathrm{yr}^{-1}$ uncertainty that is uncorrelated at distances greater than $1000 \mathrm{~km}$.

RMSE between Landsat and SAR observations (Fig. A1) setting $\sigma V_{0}=3 \mathrm{~m} \mathrm{yr}^{-1}$ and $\sigma V=1 \mathrm{~m} \mathrm{yr}^{-1}$ with a correlation length of $1000 \mathrm{~km}$ for both the SAR and Landsat mappings. Uncertainties in velocities can be as high as $20-30 \mathrm{~m} \mathrm{yr}^{-1}$ locally but are largely uncorrelated on basin scales. There are insufficient data to determine rigorous estimates of the correlation lengths for ice thickness, change in ice thickness and surface velocity, all of which are likely spatially variable. Instead we took a conservative approach and assigned a correlation length of $1000 \mathrm{~km}$ to all three measurements.

When calculating ice flux we assumed that the surface velocity was equal to the depth-averaged velocity. This approach neglects vertical gradients in ice velocity that result from the stress-dependent plastic deformation (creep) of ice. Since surface velocities are always larger than the depthaveraged velocity this introduced a positive bias into our estimates of ice flux. Neglecting sliding and assuming a depth constant creep parameter $(A)$ the depth-averaged velocity is $80 \%$ of the surface velocity (Cuffey and Paterson, 2010). Assuming parallel flow and a linear increase in shear stress with depth, the surface velocity due to creep $\left(V_{\mathrm{s}}\right)$ can be calculated as follows:

$V_{\mathrm{s}}=\frac{2 A}{1+n} t_{\mathrm{b}}^{n} H$,

where $n$ is the creep exponent, $H$ is the ice thickness and $t_{\mathrm{b}}$ is the driving stress at the bed. $n$ is typically assumed to be 3 and so is done here. $t_{\mathrm{b}}$ is calculated using the surface slope and ice depth (Cuffey and Paterson, 2010). The creep parameter $A$ (Fig. A2a) is taken from Ice Sheet System Model (ISSM) output generated as part of the Sea-level Response to Ice Sheet Evolution (SeaRISE) experiments (Bindschadler et al., 2013). We calculated surface slope from a CryoSat-2 DEM that was smoothed on a scale of several times the ice thickness $(20 \mathrm{~km})$. Ice thickness was taken from Bedmap-2 (Fretwell et al., 2013). $V_{\mathrm{s}}$ varied between $0 \mathrm{~m} \mathrm{yr}^{-1}$ at the ice divides and $10 \mathrm{~m} \mathrm{yr}^{-1}$ in steeply sloped outlet glaciers near 
(a)

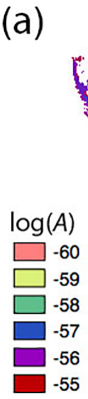

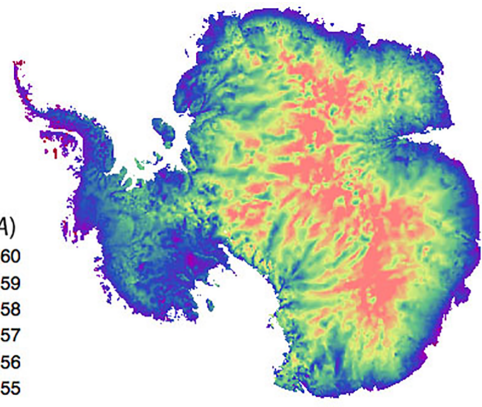

(b)

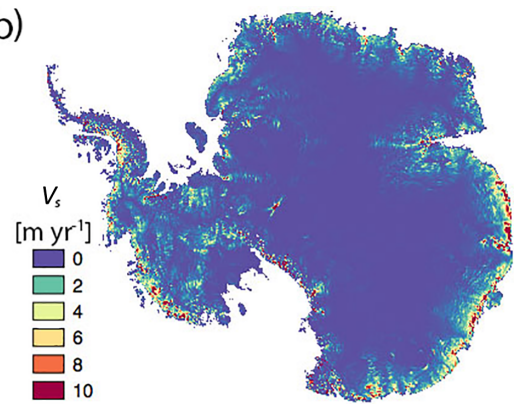

Figure A2. Creep parameter $\left(A: \mathrm{s}^{-1} \mathrm{~Pa}^{-3}\right)$ shown in log scale (a). Estimated surface velocity due to ice creep $\left(V_{\mathrm{s}}\right)$.

the coast (Fig. A2b). We considered $20 \%$ of $V_{\mathrm{s}}$ to be the upper bound of the bias introduced into our flux estimates due to vertical gradients in the velocity field $\left(\sigma F_{\bar{V}}\right)$, calculated as

$\sigma F_{\bar{V}}=0.2 \sum_{x=1}^{\mathrm{nn}} V_{\mathrm{s} i} W_{i} H_{i}$,

where $\mathrm{nn}$ is the number nodes along the basin flux gate. This is an upper bound scenario, as $A$ increases rapidly with temperature, and ice sheet temperature is typically at a maximum near the bed. This results in a higher concentration of shear deformation near the base of the ice sheet than inferred from a depth-constant $A$.

Uncertainties in flux estimates were assumed to be uncorrelated between basins. A detailed accounting of each flux term and their associated error is provided in Tables A1 through A3. Table A1 provides detailed breakdown for the total discharge calculated using FG2 as the flux gate. This approach produces the discharge estimate with the lowest error and is the approach used in the main paper. For comparison, Tables A2 and A3 provide detailed breakdowns for the total discharge calculated using FG1 and GL0, respectively.

\section{A2 Change in ice discharge}

Uncertainty in flux-change estimates $(\sigma \mathrm{d} F)$ are calculated as $\sigma \mathrm{d} F=\sqrt{\sigma \mathrm{d} F_{H}^{2}+\sigma \mathrm{d} F_{\mathrm{d} H}^{2}+\sigma \mathrm{d} F_{V}^{2}+\sigma \mathrm{d} F_{\text {no_data }}^{2}}$, where $\sigma \mathrm{d} F_{H}$ is the thickness-related uncertainty and is calculated as

$\sigma \mathrm{d} F_{H}=\sigma F_{H 0} \frac{\mathrm{d} F}{F}$,

where $\mathrm{d} F$ is the change in flux and $F$ is the total flux. $\sigma \mathrm{d} F_{\mathrm{d} H}$ is calculated in the same way as $\sigma F_{\mathrm{d} H}$ but setting $\mathrm{d} t$ to the time separation between repeat measurements of velocity. $\sigma \mathrm{d} F_{v}$ is the flux-change uncertainty from the measured velocity and is determined as

$\sigma \mathrm{d} F_{v}=\sqrt{\sigma F_{v 1}^{2}+\sigma \mathrm{d} F_{v 2}^{2}}$,

where $\sigma F_{v}$ is the uncertainty in flux introduced from uncertainties in surface velocity for two measurement epochs (1 and 2). $\sigma \mathrm{d} F_{\text {no_data }}$ is the flux-change uncertainty introduced by the assumption of zero change in flux for areas lacking reliable repeat measurements $\left(\sigma F_{\text {no_data }}\right)$ and for areas between the flux gate and the grounding line $\left(\sigma F_{\mathrm{SMB}}\right)$ and is calculated as

$\sigma \mathrm{d} F_{\text {no_data }}=0.1\left(\sigma F_{\mathrm{SMB}}+\sigma F_{\text {no_data }}\right)$.

Uncertainties in flux-change estimates were assumed to be uncorrelated between basins. A detailed accounting of each change in flux term and their associated error is provided in Table A4. 


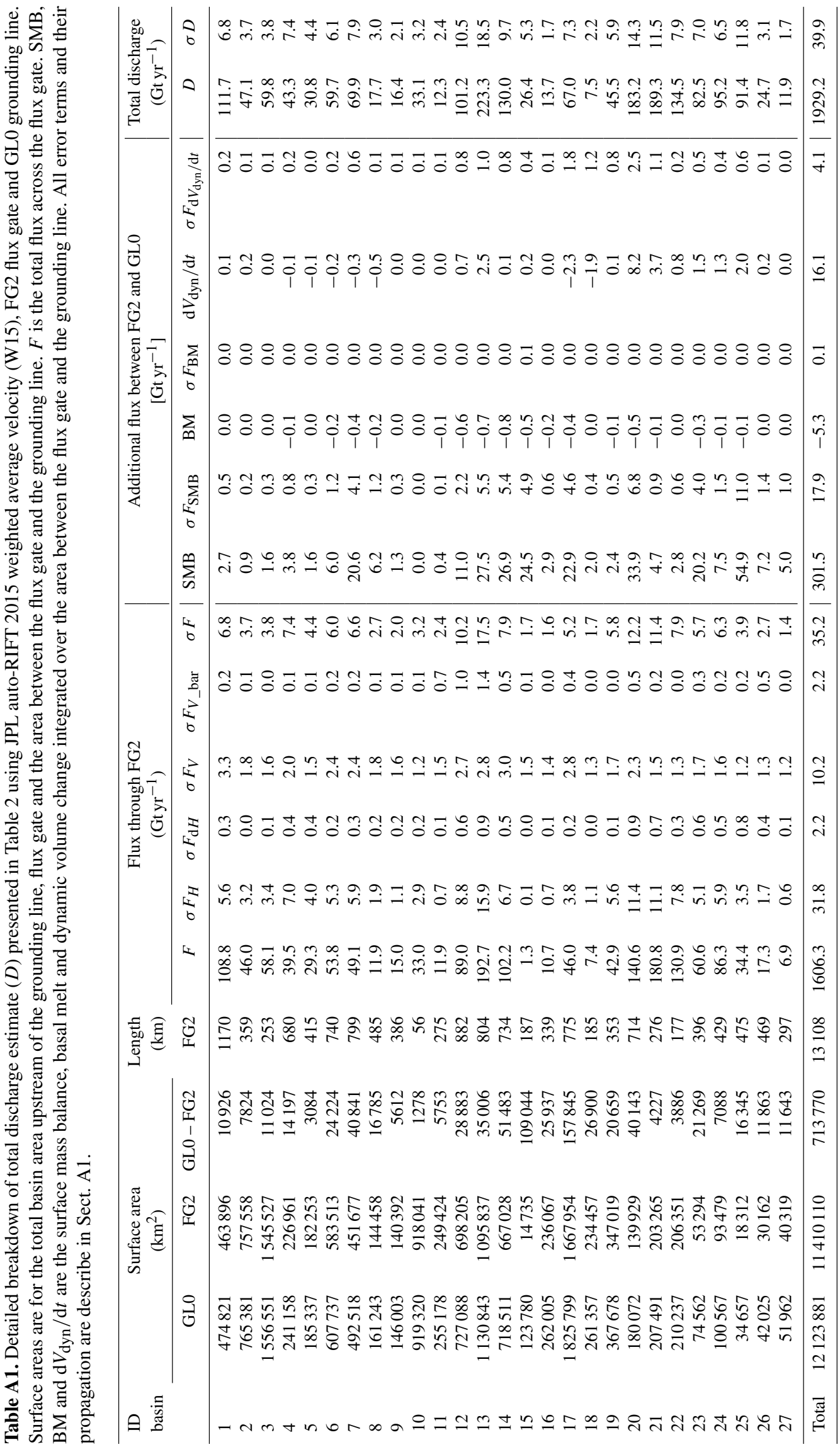



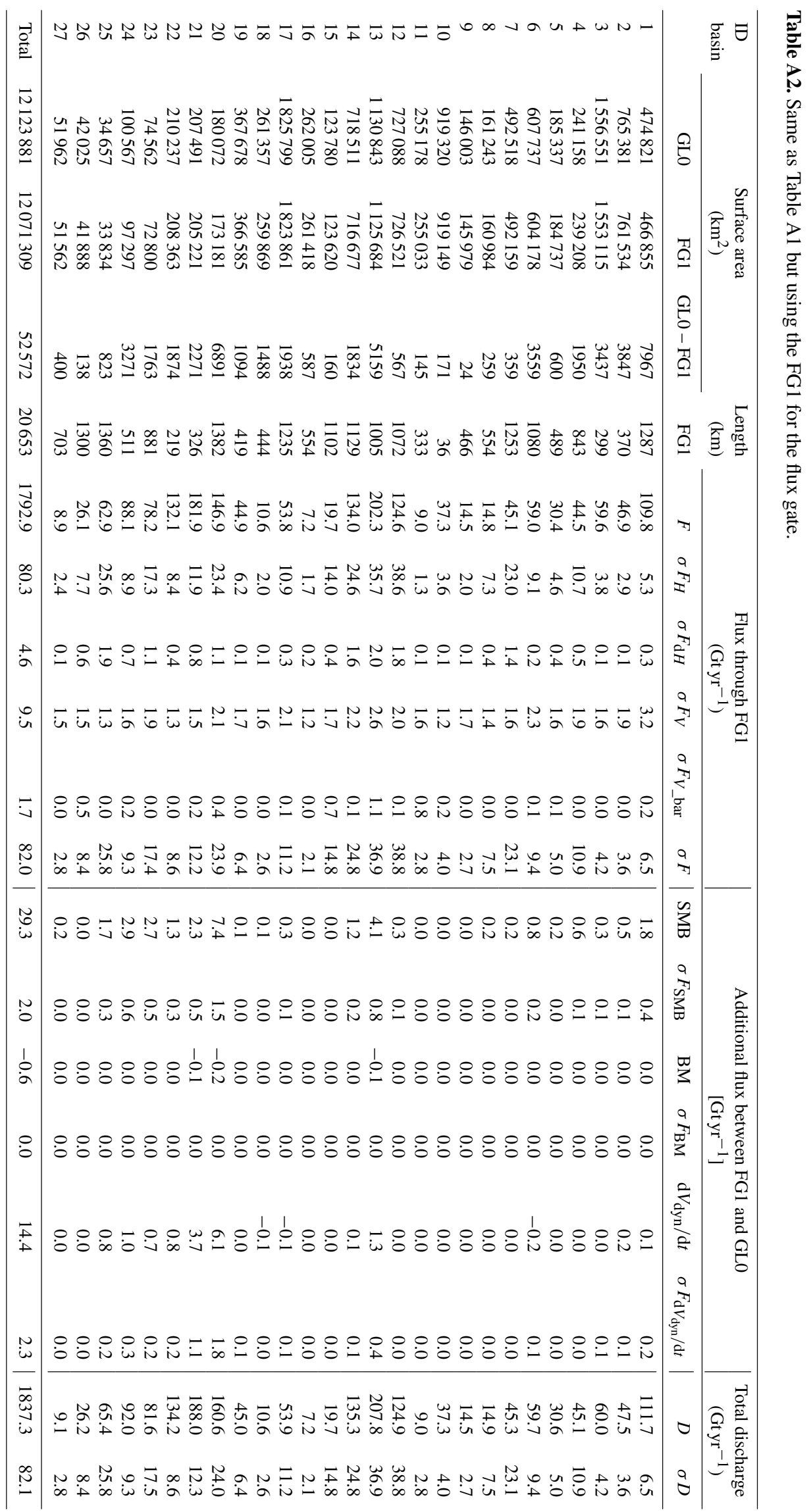


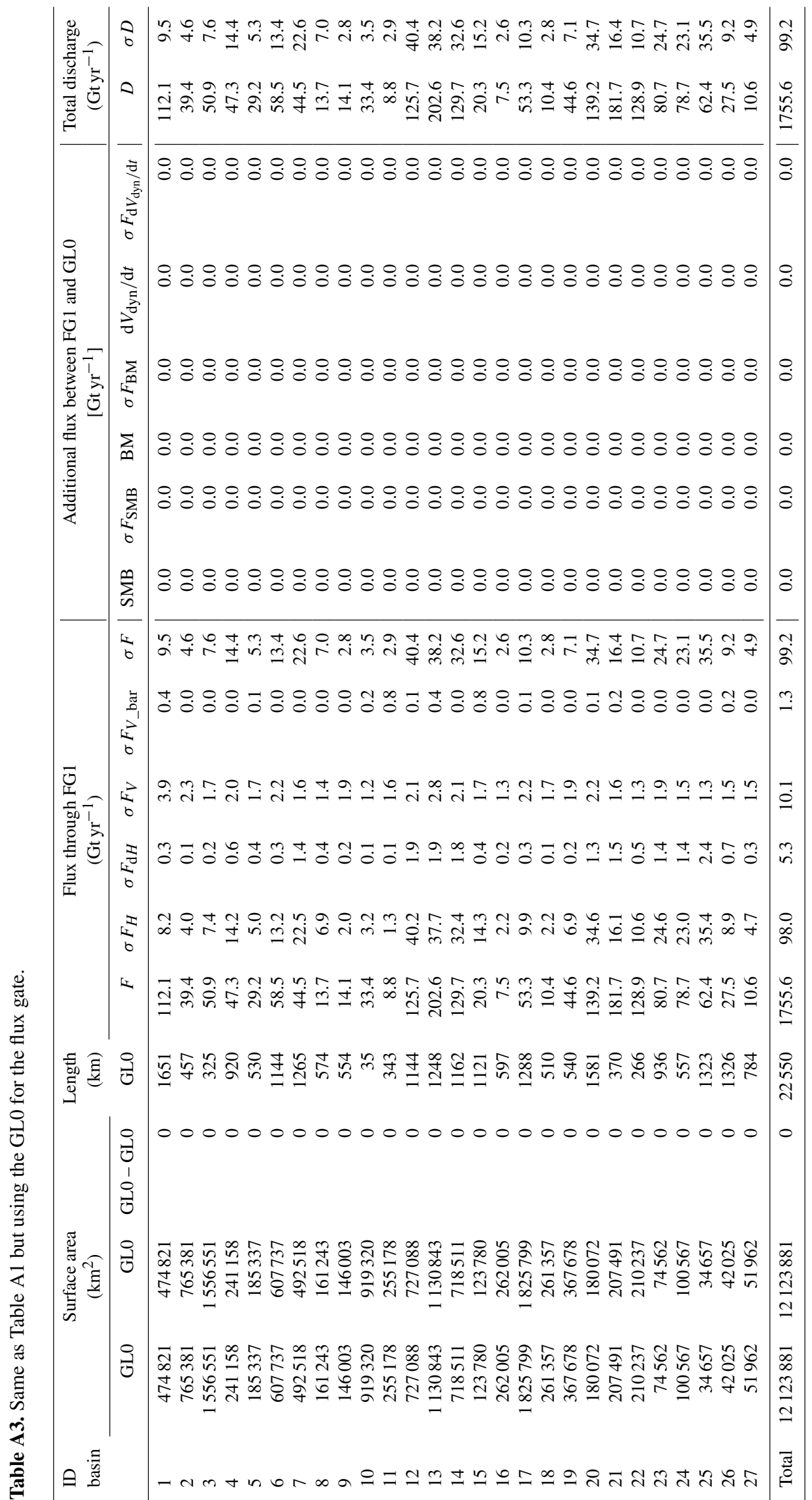


Table A4. Detailed breakdown of the change in discharge $(\Delta D)$ estimate presented in Table 2 using JPL auto-RIFT 2015 weighted average velocity (W15), 2008 velocities from Rignot et al. (2011a), the FG1 flux gate and GL0 grounding line. dF is change in flux across the grounding line and $\mathrm{dd} V_{\mathrm{dyn}} / \mathrm{d} t$ is the change in dynamic volume change for the area between FG1 and GL0. All error terms and their propagation are describe in Sect. A2.

\begin{tabular}{|c|c|c|c|c|c|c|c|c|c|c|c|c|}
\hline \multirow[t]{2}{*}{$\begin{array}{l}\text { ID } \\
\text { basin }\end{array}$} & \multicolumn{3}{|c|}{$\begin{array}{l}\text { Surface area } \\
\quad\left(\mathrm{km}^{2}\right)\end{array}$} & \multirow{2}{*}{$\begin{array}{r}\text { Length } \\
(\mathrm{km}) \\
\text { FG1 }\end{array}$} & \multicolumn{5}{|c|}{$\begin{array}{l}\Delta \text { flux through FG1 } \\
\left(\mathrm{Gt} \mathrm{yr}^{-1}\right)\end{array}$} & \multirow{2}{*}{$\begin{array}{r}\text { Additional } \Delta \text { flux between } \\
\text { FG1 and GL }\left[\mathrm{Gt} \mathrm{yr}^{-1}\right] \\
\operatorname{ddd} V_{\mathrm{dyn}} / \mathrm{d} t\end{array}$} & \multicolumn{2}{|c|}{$\begin{array}{c}\text { Total } \Delta \text { discharge } \\
\quad\left(\mathrm{Gt} \mathrm{yr}^{-1}\right)\end{array}$} \\
\hline & GL & FG1 & $\mathrm{GL}-\mathrm{FG} 1$ & & $\mathrm{~d} F$ & $\sigma \mathrm{d} F_{H}$ & $\sigma \mathrm{d} F_{\mathrm{d} H}$ & $\sigma \mathrm{d} F_{V}$ & $\sigma \mathrm{d} F_{\text {no_data }}$ & & $\mathrm{d} D$ & $\sigma \mathrm{d} D$ \\
\hline 2 & 765381 & 761534 & 3847 & 370 & -0.5 & 0.0 & 0.1 & 2.0 & 3.8 & -0.3 & -0.8 & 4.3 \\
\hline 3 & 1556551 & 1553115 & 3437 & 299 & 0.8 & 0.0 & 0.4 & 2.1 & 0.1 & -0.1 & 0.7 & 2.2 \\
\hline 4 & 241158 & 239208 & 1950 & 843 & 2.2 & 0.4 & 1.0 & 2.4 & 0.4 & 0.0 & 2.2 & 2.7 \\
\hline 5 & 185337 & 184737 & 600 & 489 & 0.7 & 0.1 & 0.8 & 2.0 & 0.3 & 0.1 & 0.7 & 2.2 \\
\hline 8 & 161243 & 160984 & 259 & 554 & 0.7 & 0.1 & 0.4 & 1.9 & 0.0 & 0.0 & 0.7 & 2.0 \\
\hline 9 & 146003 & 145979 & 24 & 466 & -0.7 & 0.1 & 0.2 & 2.2 & 0.0 & -0.1 & -0.8 & 2.2 \\
\hline 10 & 919320 & 919149 & 171 & 36 & -1.2 & 0.1 & 0.3 & 1.6 & 0.0 & 0.0 & -1.2 & 1.7 \\
\hline 11 & 255178 & 255033 & 145 & 333 & -1.2 & 0.1 & 0.1 & 2.0 & 0.0 & 0.0 & -1.1 & 2.0 \\
\hline 12 & 727088 & 726521 & 567 & 1072 & -0.3 & 0.0 & 1.3 & 2.8 & 0.4 & 0.0 & -0.3 & 3.1 \\
\hline 13 & 1130843 & 1125684 & 5159 & 1005 & -2.3 & 0.2 & 2.3 & 3.3 & 2.8 & 0.0 & -2.3 & 4.9 \\
\hline 19 & 367678 & 366585 & 1094 & 419 & 1.0 & 0.1 & 0.3 & 2.0 & 0.1 & 0.2 & 1.2 & 2.0 \\
\hline 20 & 180072 & 173181 & 6891 & 1382 & 11.6 & 0.9 & 2.6 & 2.8 & 1.1 & 0.7 & 12.2 & 4.1 \\
\hline 21 & 207491 & 205221 & 2271 & 326 & 9.4 & 0.6 & 2.8 & 2.1 & 0.2 & 0.1 & 9.5 & 3.6 \\
\hline 22 & 210237 & 208363 & 1874 & 219 & 7.2 & 0.4 & 1.1 & 1.8 & 0.1 & -0.1 & 7.1 & 2.2 \\
\hline 23 & 74562 & 72800 & 1763 & 881 & 0.1 & 0.0 & 1.7 & 2.6 & 0.5 & -0.1 & 0.0 & 3.2 \\
\hline 24 & 100567 & 97297 & 3271 & 511 & 1.7 & 0.1 & 2.1 & 2.2 & 0.4 & -0.8 & 0.8 & 3.1 \\
\hline 25 & 34657 & 33834 & 823 & 1360 & 3.6 & 0.3 & 0.9 & 1.6 & 4.3 & -0.6 & 3.0 & 4.7 \\
\hline 26 & 42025 & 41888 & 138 & 1300 & 1.7 & 0.2 & 0.9 & 2.1 & 0.4 & 0.0 & 1.7 & 2.3 \\
\hline 27 & 51962 & 51562 & 400 & 703 & 0.3 & 0.0 & 0.2 & 2.1 & 0.0 & 0.0 & 0.3 & 2.1 \\
\hline Total & 12123881 & 12071309 & 52572 & 20653 & 35.9 & 1.3 & 6.2 & 11.7 & 7.3 & -0.5 & 35.4 & 15.2 \\
\hline
\end{tabular}




\section{Appendix B: Northern Antarctic Peninsula net mass balance}

Narrow deep fjords and steep spatial and temporal gradients in surface mass balance for the northern Antarctic Peninsula (B25-26) introduced large and poorly characterized uncertainties into estimates of ice discharge and $\sigma F_{\mathrm{d} v / \mathrm{d} t}$ that propagated to highly uncertain estimates of net mass change. For this reason, we derived our estimates of net mass change using previously published estimates from repeat surface elevation measurements that we added to our estimates of change in ice discharge. Work by Scambos et al. (2014), based on elevation changes, and recent gravity work (Harig and Simons, 2015) both suggest that the northern Antarctic Peninsula region (precise study extents vary) has seen continued mass losses at more or less a constant rate of $25-30 \mathrm{Gt} \mathrm{yr}^{-1}$ for the period 2003-2015; this is further supported by examination of JPL mascon (Watkins et al., 2015) mass anomalies and RACMO surface mass budget anomalies (See Fig. B1). Estimates based on CryoSat-2 (McMillan et al., 2014) suggest a reduced mass loss for B25 and B26 (below the significance level) for the period 2010-2013, but usable data from CryoSat-2 for this rugged region are sparse.

To estimate the net mass balance for basins B25 and B26, we used estimates of glacier mass loss determined from repeat elevation measurements for the 2003-2011 period as a starting point (Scambos et al., 2014). Since this study was restricted to areas north of $66^{\circ} \mathrm{S}$, we added our estimate of change in ice discharge south of $66^{\circ} \mathrm{S}\left(6 \mathrm{Gt} \mathrm{yr}^{-1}\right.$ : Table 2$)$ to estimate the basin-wide net mass balances for 2008-2015. The uncertainty in the net budget was calculated as the RSS of the uncertainty in the basin estimate of change in discharge, the uncertainty in the net balance estimated in Scambos et al. (2014) and the uncertainty in the surface mass budget. Basin totals and uncertainties are provided in Table 2.

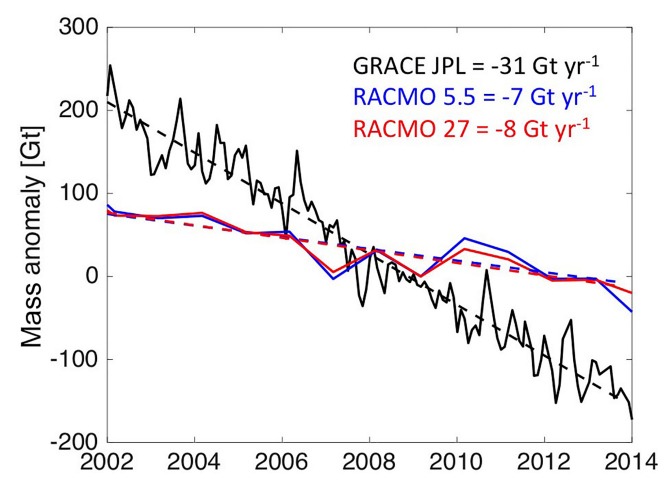

Figure B1. Rates of 2002-2014 mass change as derived from linear fits to cumulative anomalies of RACMO surface mass balance determined at $5.5 \mathrm{~km}$ (blue line) and $27 \mathrm{~km}$ (red line), and JPL V2.0 mascon anomalies (black line: http://grace.jpl.nasa.gov/data/ get-data/jpl_global_mascons/) for the northern Antarctic Peninsula. Surface mass balance and JPL mascon anomalies were integrated for the seven mascons overlapping the northern Antarctic Peninsula (4324, 4325, 4372, 4373, 4374, 4415, 4416). For plotting purposes the surface mass balance anomalies were determined relative to the 1979-2003 mean. JPL mascons are corrected for changes in solid earth using the glacial isostatic adjustment (GIA) correction modeled by Geruo A and John Wahr. This figure is provided to support the argument for a relatively steady rate of northern Antarctic Peninsula mass change between the 2003 and 2015 and not to support the magnitude of that change, which is sensitive to the choice of the model used for the GIA correction. 
Author contributions. ASG devised the study, developed the JPL auto-RIFT software, did all calculations and wrote the paper. GM was responsible for updating the grounding-line location and defining the flux gates, he also spent considerable time revising the manuscript after the lead author broke his wrist while snowboarding. TS and MF produced the LISA velocity fields; SL and MvdB provided modeled FAC and SMB output and JN produced surface elevation change rates from CryoSat- 2 data. All authors discussed and commented on the manuscript at all stages.

Competing interests. The authors declare that they have no conflict of interest.

Acknowledgements. We thank Brice Van Liefferinge and Frank Pattyn for kindly sharing their modeled estimates of basal melt rates, Bert Wouters for helpful discussions regarding Bellingshausen Sea glacier mass changes, Ala Khazendar for helping to provide context for observed changes in glacier velocity, Ian Joughin for helpful discussion regarding SAR velocities and sharing of data not used in this study, Peter Fretwell for providing information on Bedmap-2 and Eric Rignot, Jeremie Mouginot and Bernd Scheuchl for making their SAR velocities publically available, without which this study would not have been possible. Ted Scambos is deeply appreciative of Terry Haran and Marin Klinger for all of their hard work creating the NSIDC velocity maps. This work was supported by funding from the NASA Cryosphere program. The research was conducted at the Jet Propulsion Laboratory, California Institute of Technology, under contract with the National Aeronautics and Space Administration and at University of Colorado Boulder and University of Alaska Fairbanks under NASA grant NNX16AJ88G.

Edited by: G. Hilmar Gudmundsson

Reviewed by: three anonymous referees

\section{References}

Allison, I. and Hyland, G.: Amery Ice Shelf compiled and merged ice thickness datasets, Australian Antarctic Data Centre, Metadata, available at: https://data.aad.gov.au/metadata/records/AIS_ thickness_bottom (last access: 1 June 2016), 2010 (updated 2014).

Berthier, E., Scambos, T. A., and Shuman, C. A.: Mass loss of Larsen B tributary glaciers (Antarctic Peninsula) unabated since 2002, Geophys. Res. Lett., 39, L13501, https://doi.org/10.1029/2012GL051755, 2012.

Bindschadler, R. A. and Scambos, T. A.: Satellite-image-derived velocity field of an Antarctic ice stream, Science, 252, 242-246, 1991.

Bindschadler, R. A., Nowicki, S., Abe-Ouchi, A., Aschwanden, A., Choi, H., Fastook, J., Granzow, G., Greve, R., Gutowski, G., Herzfeld, U., Jackson, C., Johnson, J., Khroulev, C., Levermann, A., Lipscomb, W. H., Martin, M. A., Morlighem, M., Parizek, B. R., Pollard, D., Price, S. F., Ren, D., Saito, F., Sato, T., Seddik, H., Seroussi, H., Takahashi, K., Walker, R., and Wang, W. L.: Icesheet model sensitivities to environmental forcing and their use in projecting future sea level (the SeaRISE project), J. Glaciol., 59, 195-224, https://doi.org/10.3189/2013JoG12J125, 2013.

Blankenship, D. D., Kempf, S. D., and Young, D. A.: IceBridge HiCARS 2 L2 Geolocated Ice Thickness, Version 1, edited, NASA National Snow and Ice Data Center, Boulder, Colorado, USA, https://doi.org/10.5067/9EBR2T0VXUDG, 2012 (updated 2015).

Boening, C., Lebsock, M., Landerer, F., and Stephens, G.: Snowfalldriven mass change on the East Antarctic ice sheet, Geophys. Res. Lett., 39, L21501, https://doi.org/10.1029/2012GL053316, 2012.

Bouzinac, C.: CryoSat Product Handbook, edited, European Space Agency, available at: https://earth.esa.int/documents/ 10174/125272/CryoSat_Product_Handbook (last access: 1 June 2016), 2015.

Callens, D., Matsuoka, K., Steinhage, D., Smith, B., Witrant, E., and Pattyn, F.: Transition of flow regime along a marine-terminating outlet glacier in East Antarctica, The Cryosphere, 8, 867-875, https://doi.org/10.5194/tc-8-867-2014, 2014.

Callens, D., Thonnard, N., Lenaerts, J. T. M., Van Wessem, J. M., Van De Berg, W. J., Matsuoka, K., and Pattyn, F.: Mass balance of the Sør Rondane glacial system, East Antarctica, Ann. Glaciol., 56, 63-69, https://doi.org/10.3189/2015AoG70A010, 2015.

Christie, F. D. W., Bingham, R. G., Gourmelen, N., Tett, S. F. B., and Muto, A.: Four-decade record of pervasive grounding line retreat along the Bellingshausen margin of West Antarctica, Geophys. Res. Lett., 43, 5741-5749, https://doi.org/10.1002/2016GL068972, 2016.

Chuter, S. J., Martín-Español, A., Wouters, B., and Bamber, J. L.: Mass balance reassessment of glaciers draining into the Abbot and Getz Ice Shelves of West Antarctica, Geophys. Res. Lett., 44, 7328-7337, https://doi.org/10.1002/2017GL073087, 2017.

Cuffey, K. and Paterson, W. S. B.: The physics of glaciers, xii, 693 pp., Butterworth-Heinemann/Elsevier, Amsterdam, the Netherlands, Boston, USA, 2010.

Depoorter, M. A., Bamber, J. L., Griggs, J. A., Lenaerts, J. T. M., Ligtenberg, S. R. M., van den Broeke, M. R., and Moholdt, G.: Calving fluxes and basal melt rates of Antarctic ice shelves, Nature, 502, 89-92, https://doi.org/10.1038/nature12567, 2013.

Dutrieux, P., De Rydt, J., Jenkins, A., Holland, P. R., Ha, H. K., Lee, S. H., Steig, E. J., Ding, Q., Abrahamsen, E. P., and Schröder, M.: Strong Sensitivity of Pine Island IceShelf Melting to Climatic Variability, Science, 343, 174-178, https://doi.org/10.1126/science.1244341, 2014.

Enderlin, E. M., Howat, I. M., Jeong, S., Noh, M.-J., van Angelen, J. H., and van den Broeke, M. R.: An improved mass budget for the Greenland ice sheet, Geophys. Res. Lett., 41, 866-872, https://doi.org/10.1002/2013GL059010, 2014.

Fahnestock, M., Scambos, T., Moon, T., Gardner, A., Haran, T., and Klinger, M.: Rapid large-area mapping of ice flow using Landsat 8, Remote Sens. Environ., 185, 84-94, https://doi.org/10.1016/j.rse.2015.11.023, 2015.

Fahnestock, M., Scambos, T., Moon, T., Gardner, A., Haran, T., and Klinger, M.: Landsat8 Ice Speed of Antarctica, available at: ftp://ftp.nsidc.org/pub/DATASETS/nsidc0733_landsat_ ice_speed_v01/ (last access: 8 February 2018), 2016. 
Flament, T. and Rémy, F.: Dynamic thinning of Antarctic glaciers from along-track repeat radar altimetry, J. Glaciol., 58, 830-840, https://doi.org/10.3189/2012JoG11J118, 2012.

Fretwell, P., Pritchard, H. D., Vaughan, D. G., et al.: Bedmap2: improved ice bed, surface and thickness datasets for Antarctica, The Cryosphere, 7, 375-393, https://doi.org/10.5194/tc-7-375-2013, 2013.

Gardner, A. S., Moholdt, G., Cogley, J. G., Wouters, B., Arendt, A. A., Wahr, J., Berthier, E., Hock, R., Pfeffer, W. T., Kaser, G., Ligtenberg, S. R. M., Bolch, T., Sharp, M. J., Hagen, J. O., van den Broeke, M. R., and Paul, F.: A reconciled estimate of glacier contributions to sea level rise: 2003 to 2009 , Science, 340, 852857, https://doi.org/10.1126/science.1234532, 2013.

Gardner, A. S., Moholdt, G., Scambos, T., Fahnstock, M., Ligtenberg, S., van den Broeke, M., and Nilsson, J.: Grounding Line for Antarctic Discharge (GLAD) point files for flux estimates, available at: ftp://ftp.nsidc.org/pub/DATASETS/nsidc0732_ landsat_antarctic_ice_velocities_v01/GardnerEtA1_2018_ SupData/GLAD_flux_gates/, last access: 8 February 2018a.

Gardner, A. S., Moholdt, G., Scambos, T., Fahnstock, M., Ligtenberg, S., van den Broeke, M., and Nilsson, J.: JPL auto-RIFT v0.1 surface velocities, available at: ftp://ftp.nsidc.org/pub/ DATASETS/nsidc0732_landsat_antarctic_ice_velocities_v01/ GardnerEtAl_2018_SupData/GLAD_flux_gates/, last access: 8 February 2018 b.

Gogineni, P.: CReSIS Radar Depth Sounder Data, edited, Lawrence, Kansas, USA, avaialble at: http://data.cresis.ku.edu/ (last access: 1 June 2016), 2012 (updated 2015).

Harig, C. and Simons, F. J.: Accelerated West Antarctic ice mass loss continues to outpace East Antarctic gains, Earth Planet. Sc. Lett., 415, 134-141, https://doi.org/10.1016/j.eps1.2015.01.029, 2015.

Helm, V., Humbert, A., and Miller, H.: Elevation and elevation change of Greenland and Antarctica derived from CryoSat2, The Cryosphere, 8, 1539-1559, https://doi.org/10.5194/tc-81539-2014, 2014.

Hogg, A. E., Shepherd, A., Cornford, S. L., Briggs, K. H., Gourmelen, N., Graham, J. A., Joughin, I., Mouginot, J., Nagler, T., Payne, A. J., Rignot, E., and Wuite, J.: Increased ice flow in Western Palmer Land linked to ocean melting, Geophys. Res. Lett., 44, 4159-4167, https://doi.org/10.1002/2016GL072110, 2017.

Hulbe, C. L., Scambos, T. A., Klinger, M., and Fahnestock, M. A.: Flow variability and ongoing margin shifts on Bindschadler and MacAyeal Ice Streams, West Antarctica, J. Geophys. Res.-Earth, 121, 283-293, https://doi.org/10.1002/2015JF003670, 2016.

Huss, M. and Farinotti, D.: A high-resolution bedrock map for the Antarctic Peninsula, The Cryosphere, 8, 1261-1273, https://doi.org/10.5194/tc-8-1261-2014, 2014.

Jacobs, S., Giulivi, C., Dutrieux, P., Rignot, E., Nitsche, F., and Mouginot, J.: Getz Ice Shelf melting response to changes in ocean forcing, J. Geophys. Res.-Oceans, 118, 4152-4168, https://doi.org/10.1002/jgrc.20298, 2013.

Jacobs, S. S., Hellmer, H. H., and Jenkins, A.: Antarctic Ice Sheet melting in the southeast Pacific, Geophys. Res. Lett., 23, 957960, https://doi.org/10.1029/96GL00723, 1996.

Jacobs, S. S., Jenkins, A., Giulivi, C. F., and Dutrieux, P.: Stronger ocean circulation and increased melting under Pine Island Glacier ice shelf, Supplement, Nat. Geosci., 4, 519-523, https://doi.org/10.1038/ngeo1188, 2011.
Jenkins, A., Vaughan, D. G., Jacobs, S. S., Hellmer, H. H., and Keys, J. R.: Glaciological and oceanographic evidence of high melt rates beneath Pine Island Glacier, West Antarctica, J. Glaciol., 43, 114-121, 1997.

Jeong, S. and Howat, I. M.: Performance of Landsat 8 Operational Land Imager for mapping ice sheet velocity, Remote Sens. Environ., 170, 90-101, https://doi.org/10.1016/j.rse.2015.08.023, 2015.

Jezek, K. C., Farness, K., Carande, R., Wu, X., and LabelleHamer, N.: RADARSAT 1 synthetic aperture radar observations of Antarctica: Modified Antarctic Mapping Mission, 2000, Radio Sci., 38, 8067, https://doi.org/10.1029/2002RS002643, 2003.

Khazendar, A., Borstad, C. P., Scheuchl, B., Rignot, E., and Seroussi, H.: The evolving instability of the remnant Larsen B Ice Shelf and its tributary glaciers, Earth Planet. Sc. Lett., 419, 199-210, https://doi.org/10.1016/j.epsl.2015.03.014, 2015.

Khazendar, A., Rignot, E., Schroeder, D. M., Seroussi, H., Schodlok, M. P., Scheuchl, B., Mouginot, J., Sutterley, T. C., and Velicogna, I.: Rapid submarine ice melting in the grounding zones of ice shelves in West Antarctica, Supplement, Nat. Commun., 7, 13243, https://doi.org/10.1038/ncomms13243, 2016.

King, M. A., Bingham, R. J., Moore, P., Whitehouse, P. L., Bentley, M. J., and Milne, G. A.: Lower satellite-gravimetry estimates of Antarctic sea-level contribution, Supplement, Nature, 491, 586589, https://doi.org/10.1038/nature11621, 2012.

Konrad, H., Gilbert, L., Cornford, S. L., Payne, A., Hogg, A., Muir, A., and Shepherd, A.: Uneven onset and pace of ice-dynamical imbalance in the Amundsen Sea Embayment, West Antarctica, Geophys. Res. Lett., 44, 910-918, https://doi.org/10.1002/2016GL070733, 2017.

Leuschen, C., Gogineni, P., Rodriguez-Morales, F., Paden, J., and Allen, C.: IceBridge MCoRDS L2 Ice Thickness, Version 1, edited, NASA National Snow and Ice Data Center, Boulder, Colorado, USA, https://doi.org/10.5067/GDQ0CUCVTE2Q, 2010 (updated 2015).

Li, X., Rignot, E., Morlighem, M., Mouginot, J., and Scheuchl, B.: Grounding line retreat of Totten Glacier, East Antarctica, 1996 to 2013, Geophys. Res. Lett., 42, 8049-8056, https://doi.org/10.1002/2015GL065701, 2015.

Li, X., Rignot, E., Mouginot, J., and Scheuchl, B.: Ice flow dynamics and mass loss of Totten Glacier, East Antarctica, from 1989 to 2015, Geophys. Res. Lett., 43, 6366-6373, https://doi.org/10.1002/2016GL069173, 2016.

Ligtenberg, S. R. M., Helsen, M. M., and van den Broeke, M. R.: An improved semi-empirical model for the densification of Antarctic firn, The Cryosphere, 5, 809-819, https://doi.org/10.5194/tc-5809-2011, 2011.

Ligtenberg, S. R. M., Kuipers Munneke, P., and van den Broeke, M. R.: Present and future variations in Antarctic firn air content, The Cryosphere, 8, 1711-1723, https://doi.org/10.5194/tc8-1711-2014, 2014.

Macgregor, J. A., Catania, G. A., Markowski, M. S., and Andrews, A. G.: Widespread rifting and retreat of ice-shelf margins in the eastern Amundsen Sea Embayment between 1972 and 2011, J. Glaciol., 58, 458-466, https://doi.org/10.3189/2012JoG11J262, 2012.

Martín-Español, A., Zammit-Mangion, A., Clarke, P. J., Flament, T., Helm, V., King, M. A., Luthcke, S. B., Petrie, E., Rémy, F., Schön, N., Wouters, B., and. Bamber, J. L: Spatial and tempo- 
ral Antarctic Ice Sheet mass trends, glacio-isostatic adjustment, and surface processes from a joint inversion of satellite altimeter, gravity, and GPS data, J. Geophys. Res.-Earth, 121, 182-200, https://doi.org/10.1002/2015JF003550, 2016.

McMillan, M., Shepherd, A., Sundal, A., Briggs, K., Muir, A., Ridout, A., Hogg, A., and Wingham, D.: Increased ice losses from Antarctica detected by CryoSat-2, Geophys. Res. Lett., 41, 3899-3905, https://doi.org/10.1002/2014GL060111, 2014.

Morlighem, M., Rignot, E., Seroussi, H., Larour, E., Ben Dhia, H., and Aubry, D.: A mass conservation approach for mapping glacier ice thickness, Geophys. Res. Lett., 38, L19503, https://doi.org/10.1029/2011GL048659, 2011.

Mouginot, J., Rignot, E., and Scheuchl, B.: Sustained increase in ice discharge from the Amundsen Sea Embayment, West Antarctica, from 1973 to 2013, Geophys. Res. Lett., 41, 1576-1584, https://doi.org/10.1002/2013GL059069, 2014.

Mouginot, J., Rignot, E., Scheuchl, B., and Millan, R.: Comprehensive Annual Ice Sheet Velocity Mapping Using Landsat-8, Sentinel-1, and RADARSAT-2 Data, Remote Sensing, 9, 364, https://doi.org/10.3390/rs9040364, 2017.

Nilsson, J., Gardner, A., Sandberg Sørensen, L., and Forsberg, R.: Improved retrieval of land ice topography from CryoSat-2 data and its impact for volume-change estimation of the Greenland Ice Sheet, The Cryosphere, 10, 2953-2969, https://doi.org/10.5194/tc-10-2953-2016, 2016.

Padman, L., Erofeeva, S. Y., and Fricker, H. A.: Improving Antarctic tide models by assimilation of ICESat laser altimetry over ice shelves, Geophys. Res. Lett., 35, L22504, https://doi.org/10.1029/2008GL035592, 2008.

Paolo, F. S., Fricker, H. A., and Padman, L.: Volume loss from Antarctic ice shelves is accelerating, Science, 348, 327-331, https://doi.org/10.1126/science.aaa0940, 2015.

Paragios, N., Chen, Y., and Faugeras, O. D.: Handbook of mathematical models in computer vision, Springer Science \& Business Media, New York, NY, USA, 2006.

Pattyn, F.: Antarctic subglacial conditions inferred from a hybrid ice sheet/ice stream model, Earth Planet. Sc. Lett., 295, 451-461, https://doi.org/10.1016/j.epsl.2010.04.025, 2010.

Pritchard, H. D., Arthern, R. J., Vaughan, D. G., and Edwards, L. A.: Extensive dynamic thinning on the margins of the Greenland and Antarctic ice sheets, Nature, 461, 971-975, 2009.

Pritchard, H. D., Ligtenberg, S. R. M., Fricker, H. A., Vaughan, D. G., van den Broeke, M. R., and Padman, L.: Antarctic ice-sheet loss driven by basal melting of ice shelves, Supplement, Nature, 484, 502-505, https://doi.org/10.1038/nature10968, 2012.

Rignot, E.: Changes in ice dynamics and mass balance of the Antarctic ice sheet, Philos. T. Roy. Soc. Lond. A, 364, 16371655, https://doi.org/10.1098/rsta.2006.1793, 2006.

Rignot, E. and Thomas, R. H.: Mass balance of Polar ice sheets, Science, 297, 1502-1506, 2002.

Rignot, E., Mouginot, J., and Scheuchl, B.: Ice Flow of the Antarctic Ice Sheet, Science, 333, 1427-1430, https://doi.org/10.1126/science.1208336, 2011a.

Rignot, E., Velicogna, I., van den Broeke, M. R., Monaghan, A., and Lenaerts, J.: Acceleration of the contribution of the Greenland and Antarctic ice sheets to sea level rise, Geophys. Res. Lett., 38, L05503, https://doi.org/10.1029/2011g1046583, 2011 b.
Rignot, E., Jacobs, S., Mouginot, J., and Scheuchl, B.: IceShelf Melting Around Antarctica, Science, 341, 266-270, https://doi.org/10.1126/science.1235798, 2013.

Rignot, E., Mouginot, J., Morlighem, M., Seroussi, H., and Scheuchl, B.: Widespread, rapid grounding line retreat of Pine Island, Thwaites, Smith, and Kohler glaciers, West Antarctica, from 1992 to 2011, Geophys. Res. Lett., 41, 3502-3509, https://doi.org/10.1002/2014GL060140, 2014.

Scambos, T. A., Dutkiewicz, M. J., Wilson, J. C., and Bindschadler, R. A.: Application of Image Cross-Correlation to the Measurement of Glacier Velocity Using Satellite Image Data, Remote Sens. Environ., 42, 177-186, 1992.

Scambos, T. A., Haran, T. M., Fahnestock, M. A., Painter, T. H., and Bohlander, J.: MODIS-based Mosaic of Antarctica (MOA) data sets: Continent-wide surface morphology and snow grain size, Remote Sens. Environ., 111, 242-257, https://doi.org/10.1016/j.rse.2006.12.020, 2007.

Scambos, T. A., Berthier, E., Haran, T., Shuman, C. A., Cook, A. J., Ligtenberg, S. R. M., and Bohlander, J.: Detailed ice loss pattern in the northern Antarctic Peninsula: widespread decline driven by ice front retreats, The Cryosphere, 8, 2135-2145, https://doi.org/10.5194/tc-8-2135-2014, 2014.

Scheuchl, B., Mouginot, J., and Rignot, E.: Ice velocity changes in the Ross and Ronne sectors observed using satellite radar data from 1997 and 2009, The Cryosphere, 6, 1019-1030, https://doi.org/10.5194/tc-6-1019-2012, 2012.

Scheuchl, B., Mouginot, J., Rignot, E., Morlighem, M., and Khazendar, A.: Grounding line retreat of Pope, Smith, and Kohler Glaciers, West Antarctica, measured with Sentinel-1a radar interferometry data, Geophys. Res. Lett., 43, 8572-8579, https://doi.org/10.1002/2016GL069287, 2016.

Shepherd, A., Ivins, E. R., A, G., et al.: A Reconciled Estimate of Ice-Sheet Mass Balance, Science, 338, 1183-1189, https://doi.org/10.1126/science.1228102, 2012.

Shuman, C. A., Berthier, E., and Scambos, T. A.: 20012009 elevation and mass losses in the Larsen A and B embayments, Antarctic Peninsula, J. Glaciol., 57, 737-754, https://doi.org/10.3189/002214311797409811, 2017.

Smith, J. A., Andersen, T. J., Shortt, M., Gaffney, A. M., Truffer, M., Stanton, T. P., Bindschadler, R., Dutrieux, P., Jenkins, A., Hillenbrand, C. D., Ehrmann, W., Corr, H. F. J., Farley, N., Crowhurst, S., and Vaughan, D. G.: Sub-ice-shelf sediments record history of twentieth-century retreat of Pine Island Glacier, Nature, 541, 77-80, https://doi.org/10.1038/nature20136, 2017.

Snyder, J. P.: Map projections: A working manual, Report Rep. 1395, U. S. Government Printing Office, Washington, D.C, USA, 1987.

Thomson, J. and Cooper, A.: The SCAR Antarctic digital topographic database, Antarct. Sci., 5, 239-244, 1993.

Van Liefferinge, B. and Pattyn, F.: Using ice-flow models to evaluate potential sites of million year-old ice in Antarctica, Clim. Past, 9, 2335-2345, https://doi.org/10.5194/cp-9-23352013, 2013.

van Wessem, J. M., Reijmer, C. H., Morlighem, M., Mouginot, J., Rignot, E., Medley, B., Joughin, I., Wouters, B., Depoorter, M. A., Bamber, J. L., Lenaerts, J. T. M., De Van Berg, W. J., Van Den Broeke, M. R., and Van Meijgaard, E.: Improved representation of East Antarctic surface mass balance in a re- 
gional atmospheric climate model, J. Glaciol., 60, 761-770, https://doi.org/10.3189/2014JoG14J051, 2014.

van Wessem, J. M., Ligtenberg, S. R. M., Reijmer, C. H., van de Berg, W. J., van den Broeke, M. R., Barrand, N. E., Thomas, E. R., Turner, J., Wuite, J., Scambos, T. A., and van Meijgaard, E.: The modelled surface mass balance of the Antarctic Peninsula at $5.5 \mathrm{~km}$ horizontal resolution, The Cryosphere, 10, 271-285, https://doi.org/10.5194/tc-10-271-2016, 2016.

Velicogna, I.: Increasing rates of ice mass loss from the Greenland and Antarctic ice sheets revealed by GRACE, Geophys. Res. Lett., 36, L19503, https://doi.org/10.1029/2009g1040222, 2009.

Walker, C. C. and Gardner, A. S.: Rapid drawdown of Antarctica's Wordie Ice Shelf glaciers in response to ENSO/Southern Annular Mode-driven warming in the Southern Ocean, Supplement C, Earth Planet. Sc. Lett., 476, 100-110, https://doi.org/10.1016/j.epsl.2017.08.005, 2017.

Watkins, M. M., Wiese, D. N., Yuan, D.-N., Boening, C., and Landerer, F. W.: Improved methods for observing Earth's time variable mass distribution with GRACE using spherical cap mascons, J. Geophys. Res.-Sol. Ea., 120, 2648-2671, https://doi.org/10.1002/2014JB011547, 2015.
Wouters, B., Martin-Español, A., Helm, V., Flament, T., van Wessem, J. M., Ligtenberg, S. R. M., van den Broeke, M. R., and Bamber, J. L.: Dynamic thinning of glaciers on the Southern Antarctic Peninsula, Science, 348, 899-903, https://doi.org/10.1126/science.aaa5727, 2015.

Wuite, J., Rott, H., Hetzenecker, M., Floricioiu, D., De Rydt, J., Gudmundsson, G. H., Nagler, T., and Kern, M.: Evolution of surface velocities and ice discharge of Larsen B outlet glaciers from 1995 to 2013, The Cryosphere, 9, 957-969, https://doi.org/10.5194/tc-9-957-2015, 2015.

Zwally, H. J., Giovinetto, B. M., Beckley, M. A., and Saba, J. L.: Antarctic and Greenland Drainage Systems, GSFC Cryospheric Sciences Laboratory, available at: http://icesat4.gsfc.nasa.gov/ cryo_data/ant_grn_drainage_systems.php (last access: 1 June 2016), 2002. 